Portland State University

PDXScholar

1992

\title{
L'être et le Paraître à travers cinq romans de Raymond Queneau
}

\author{
Mireille J. Balland \\ Portland State University
}

Follow this and additional works at: https://pdxscholar.library.pdx.edu/open_access_etds

Part of the French and Francophone Literature Commons Let us know how access to this document benefits you.

\section{Recommended Citation}

Balland, Mireille J., "Lêtre et le Paraître à travers cinq romans de Raymond Queneau" (1992). Dissertations and Theses. Paper 4220.

https://doi.org/10.15760/etd.6106

This Thesis is brought to you for free and open access. It has been accepted for inclusion in Dissertations and Theses by an authorized administrator of PDXScholar. Please contact us if we can make this document more accessible: pdxscholar@pdx.edu. 
AN ABSTRACT OF THE THESIS OF Mireille J. Balland for the Master of Arts in Foreign Languages: French presented May 8, 1992.

Title: L'être et le Paraître à travers cinq romans de Raymond Queneau.

APPROVED BY MEMBERS OF THE THESIS COMMITTEE:

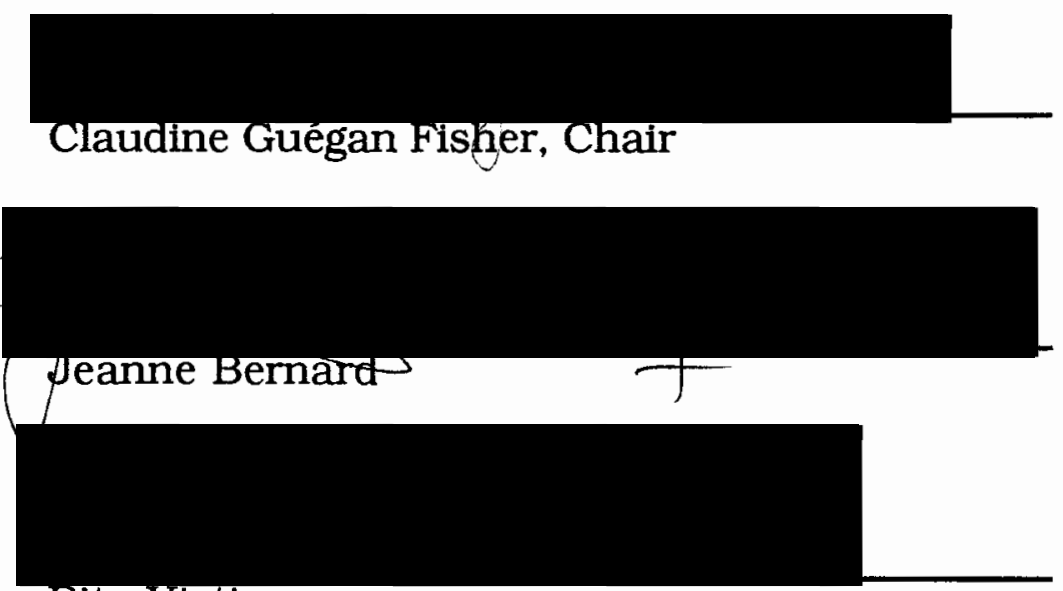

Rita Vistica

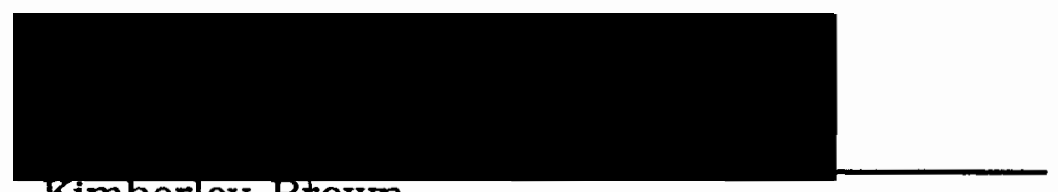

Kimberley Brown

The writings of Raymond Queneau span a period of more than forty years and reflect the multiplicity of his approaches: essays, songs, poems, scenarios for the cinema, translations (from English to French), journal, and novels.

My study focuses mainly on five novels: Le Chiendent (The Bark Tree), Les Fleurs bleues (Between Blue and Blue), Le Dimanche de la 
vie (The Sunday of Life), Pierrot mon ami (Pierrot) and Zazie dans le métro (Zazie in the Metro), the one that made him known to a wide reading audience. Gueneau contributed to the very rich philosophical and literary scene in France sandwiched between twentieth century surrealism and existentialism, drawing much of his inspiration from the popular characters of the every day Parisian life.

My thesis mainly focuses on Queneau's dichotomy between "what is" and "what appears to be". Because of Queneau's extreme versatility, I do not attempt to analyze every aspect of his writing but limit it to examining his concept of appearance and reality, an approach which cuts accross various aspects of his writing.

The first chapter outlines the interplay between the sciences, literature and the concept of humor interpreted in the light of a notion of a participatory rather than a passive reading.

The second chapter, entitled "Le Défi du Langage" (The Challenge of Language), elaborates upon Queneau's "fantasy" world with a concentration on the linguistic elements and play-on-words.

The third chapter, entitled "La Valeur Structurelle" (The Structural Value), deals with the way in which Gueneau structures his novels and the different forms taken by his fiction: examination of the symbolic aspect of numbers and forms; echos and symmetry; dream and reality; repetitions and play on the "I/eye".

The fourth chapter, entitled "L'Etre et le Paraitre" (Being and Appearing), answers the main question of appearance and reality while dealing with the philosophy of "being or not being" as well as the resulting corollary of realizing anguish and death. Queneau's 
characters answer to these eternal questions through a growing awareness and consciousness which drive them to espousing anonymity or popular wisdom. In so doing, Queneau's humor enlarges upon the parody of philosophers such as Parmenides, Plato, Descartes, Camus or Sartre.

In the conclusion, entitled "Au-delà de l'humour" (Beyond Humor), Queneau's laughter which is omnipresent, expresses the underlying condition through his observation of particular individuals in their very individualities. In the final analysis, Queneau's humanism shines forth with great empathy, comprehension, and humility. 


\title{
L'ÊTRE ET LE PARAÎTRE A TRAVERS CINQ ROMANS DE RAYMOND QUENEAU
}

\author{
by \\ MIREILLE J. BALLAND
}

A thesis submitted in partial fulfillment of the requirements for the degree of

\author{
MASTER OF ARTS \\ in \\ FOREIGN LANGUAGES: FRENCH
}

Portland State University

1992 
TO THE OFFICE OF GRADUATE STUDIES:

The members of the committee approve the thesis of Mireille J. Balland presented May 8, 1992.

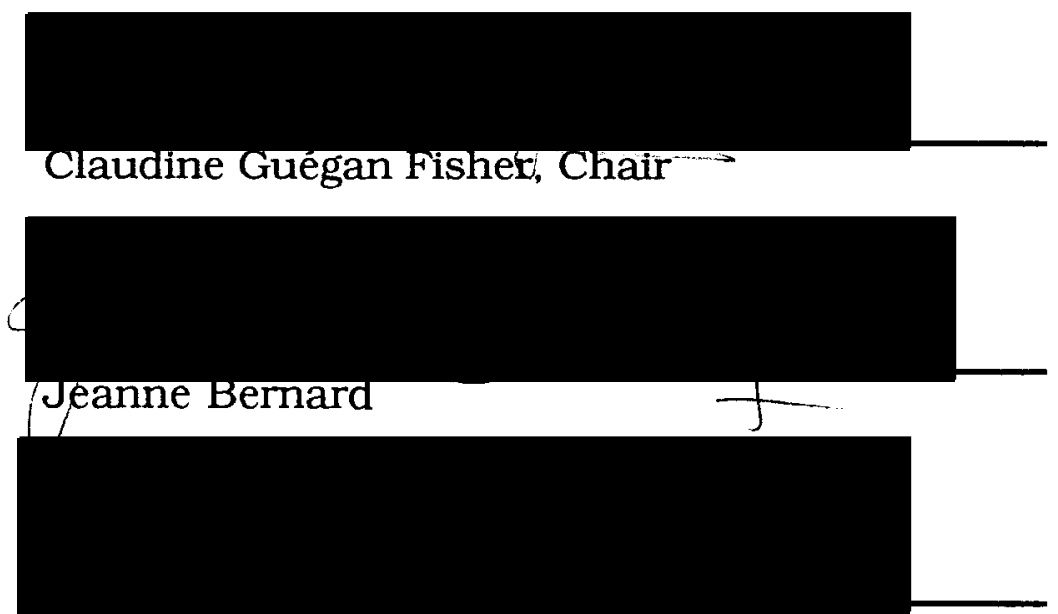

Rita Vistica

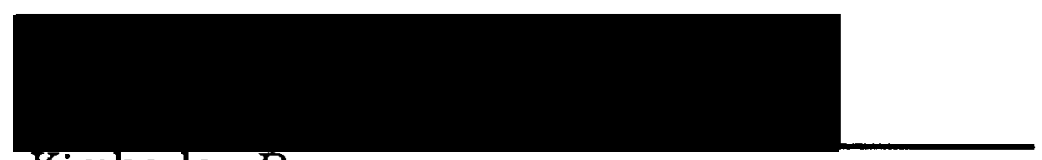

Kimberley Brown

APPROVED:

Linda Parshall, Chair, Department of Foreign Languages and Literatures

C. William Savery, Interim Vice Provgst for Graduate Studies and Research 


\section{A Elodie}

Il jugea bon d'agrémenter ce remerciement un peu trop sec... par un peu du lait de la tendresse humaine.

- Raymond Queneau,

Le Dimanche de la vie 


\section{ACKNOWLEDGMENTS}

Thanks are due to many generous people without whose help this thesis would not have been written.

I would like to express my sincere appreciation to Professor Rita Vistica, a highly valued advisor, who incited me to take upon this thesis and continually encouraged me from beginning to end.

My deep appreciation goes to Professor Claudine Guégan Fisher who inspired me to rediscover the works of Raymond Queneau. Through several lengthy sessions, she has been enormously helpful with thought-provoking suggestions, and guidance in the writing of this thesis.

I am also grateful to Professors Jeanne Bernard and Eric Swenson for all the help they have given me throughout my studies at Portland State University.

My students will always be remembered for leading me to become fully aware of the subtlety and idiosyncrasies of my native language.

Many thanks to my sister, Annick, who helped me gather valuable materials.

Finally, a very special thanks to my husband, Jean-Claude, for his support, sincere interest in my work, and help in piercing the secrets of the (electronic) mouse. 


\section{TABLE OF CONTENTS}

\section{PAGE}

ACKNOWLEDGEMENTS.

iii

\section{CHAPTER}

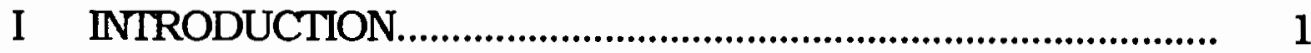

II LE DËFI DU LANGAGE.................................................... 10

Invention verbale ........................................................ 10

Code de l'écriture........................................................ 24

III LA SYMBOLIGUE STRUCTURELLE................................... 29

Nombres et forme.................................................... 29

Échos et symétries....................................................... 35

Rêve et réalité.............................................................. 40

Répétition et jeu du "je"................................................ 43

IV L'ÊTRE ET LE PARAÎTRE................................................. 49

Apparence et réalité.................................................... 49

Existence et non-existence...................................... 57

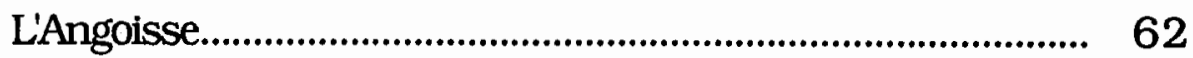

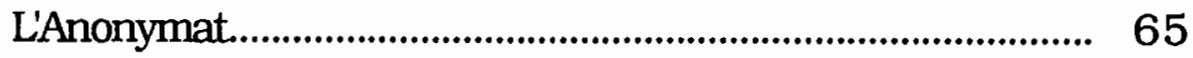

Sagesse populaire........................................................ 69

V AU-DELA DE L'HUMOUR................................................. 77 
OUVRAGES CONSULTÉS............................................................... 82

APPENDICES

A BIOGRAPHIE DE RAYMOND gUENEAU.................... 85

B ABBRÉVIATIONS UTILISÉES POUR LES OEUVRES

DE QUENEAU CITÉES EN RÉFÉRENCES................ 93 


\section{CHAPITRE I}

\section{INTRODUCTION}

N'oubliez pas l'art tout de même. Y a pas que la rigolade, y a aussi l'art... avec un grand $a$, faites bien gaffe!

- Raymond Queneau, Zazie dans le métro

Raymond Queneau est l'un des rares auteurs du XXe siècle qui se soit intéressé au besoin de communication et d'échanges entre sciences et littérature, déplorant leur quasi inexistence dans la culture occidentale contemporaine. Il critiquait notamment le préjugé "littéraire" qui consiste à dire avec satisfaction, "Moi je ne comprends rien aux mathématiques." Selon lui, l'art n'est pas un rival de la science, il ne doit pas se recroqueviller sur lui-même; il a la capacité d'étendre ses limites à l'infini et d'y inclure en les exprimant dans un langage accessible à tous, tous les aspects de l'activité humaine. L'art, la poésie, la littérature sont une part intégrale de la société et une force capable de transformer la réalité sociale (V.G. 94). Petite cosmogonie portative, parue en 1950 , est un recueil de poèmes où la science est envisagée comme thème poétique (B.c.l. 47), et qui a l'ambition d'élargir et de rehausser la vision des valeurs sociétales de la poésie. Il ne s'agit pas d'instruire, mais de créer et cette création est véhiculée par le langage. Queneau y joue avec les termes scientifiques qu'il mélange à ceux de la mythologie, de la poésie, de 
l'argot, de la littérature, des langues étrangères, du français parlé, de l'orthographe phonétique, pour créer un effet de richesse, d'effervescence, de force, d'accumulation, d'abondance, de vie, d'énigme, de mouvement, de merveilleux et d'imitation mystérieuse des procédés de création et d'évolution qu'il tente de décrire; témoins ces alexandrins de la Petite cosmogonie portative:

On parle de Minos et de Pasiphae du pélican lassé qui revient d'un voyage du vierge du vivace et du bel aujourd'hui on parle d'albatros aux ailes de géant de bateaux descendant des fleuves impassibles d'enfants qui dans le noir volent des étincelles alors pourquoi pas de l'électromagnétisme ce n'est pas qu'il (c'est moi) sache très bien ce xé les autres savaient-ils ce xétait que les roses l'albatros le voyage un enfant un bateau.... (P.c.p. 61)

Le jeu de mots, si cher à Queneau, est la réunification inattendue de deux significations séparées qui permet d'avoir une nouvelle vision du langage et du référent. De plus, le langage doit continuellement se renouveler pour éviter de devenir automatique, de (re)présenter le monde toujours dans les mêmes termes et donc de perdre son pouvoir magique qui permet à chacun d'en modifier sa perception. Un autre "poème scientifique", Le Chant du styrène, fut écrit dans les années 60, à la demande du cinéaste Alain Resnais qui en a fait un courtmétrage publicitaire pour la société de produits chimiques Péchiney ${ }^{1}$. Soixante dix- huit alexandrins décrivent l'histoire du bol en plastique (styrène) de façon humoristique par l'usage de termes scientifiques et littéraires, de jeux de mots, d'allusions intertextuelles aux oeuvres de 
l'auteur lui-même et à celles d'autres auteurs ("O temps suspends ton bol" ouvre le slogan), de répétitions des sons et de questions métaphysiques sur "l'origine obscure des éléments".

Le goût de Queneau pour les sciences et les mathématiques, leur relation avec le langage et l'esprit, est très présent également dans plusieurs de ses romans, particulièrement Gueule de Pierre, Odile et Les Enfants du Limon. Avec sa participation active au groupe de l'OuLiPo', Queneau a étudié des structures qui permettraient de faire des oeuvres de qualité après avoir découvert, à travers l'analyse d'oeuvres littéraires, que les textes ont un autre contenu que celui que l'on croit, si on analyse de près les principes de leur structure. Selon lui, tout texte est construit selon des contraintes formelles, que l'auteur en ait conscience ou pas. Le surréalisme rejette la raison humaine et la connaissance consciente comme base de l'art, il privilégie la science de la psychanalyse, l'importance de l'inconscient et du non construit. Queneau précise: "Toute littérature digne de ce nom se refuse au relâchement automatisme scribal, laisser-aller inconstructif" (V.G. 83). Il s'élève contre l'équivalence établie entre inspiration, exploration du subconscient et libération, entre hasard, automatisme et liberté;

Le classique qui écrit sa tragédie en observant un certain nombre de règles qu'il connait est plus libre que le poète qui écrit ce qui lui passe par la tête et qui est esclave d'autres règles qu'il ignore. (V.G. 94)

1 Ouvroir de la Littérature Potentielle qui comporte d'éminents mathématiciens, écrlvains tels que George Pérec, et untversitaires françads et étrangers, et quil continue à exister de nos jours. 
Les poètes de la Renaissance en recherchant des formes très précises ont prouvé que la cohérence interne était une nécessité. Même si l'oeuvre de Queneau peut sembler bizarre, inattendue, surprenante et fantastique comme celle des surréalistes, les conditions de sa composition sont tout à fait autres, "l'apparence est surréaliste mais la méthode ne l'est pas. L'automatisme n'a rien à voir avec l'écriture automatique surréaliste" (Charbonnier 147). Queneau, par contre, fonde ses écrits sur le principe de la beauté de la connaissance et sur l'utilisation de structures mathématiques pour inventer des formes capables de synthétiser, de transmettre et même de créer une connaissance qu'il serait impossible d'obtenir par les auteurs qui dépendent uniquement de l'"inspiration" capricieuse de leur inconscient. Cent Mille Milliards de poèmes et Exercices de style sont certainement des exemples de la multiplicité des possibilités littéraires. François Le Lionnais, le fondateur de l'OuLiPo, écrivait dans la postface du premier:

Avec les Exercices de style et le présent recueil, elle (la littérature expérimentale) entend sortir de cette semiclandestinité, affirmer sa légitimité, proclamer ses ambitions, se constituer des méthodes, bref s'accorder à notre civilisation scientifique. (127)

Cent Mille Milliards de poèmes ont été écrits à partir de dix sonnets organisés autour des mêmes rimes et des mêmes structures syntaxiques; les vers ont été découpés de telle sorte que la libre combinaison de chaque vers avec les treize autres forme un recueil de $10^{14}$ sonnets.

Une trentaine d'années se sont écoulées depuis la rupture de Queneau avec André Breton, pour des raisons personnelles (dira 
l'auteur) et sans nul doute idéologiques. Néanmoins, son passage dans le groupe n'a pas pu le laisser indifférent; il reconnaissait d'ailleurs plus tard que le surréalisme avait permis une nouvelle conception de la poésie même si déjà à cette époque, il n'attribuait pas la même fonction à l'écriture et au langage. Queneau a lui-même publié dans la Révolution surréaliste et l'automatisme psychique a laissé son empreinte particulièrement au niveau de ses premiers poèmes, $\underline{\text { Les }}$ Ziaux en particulier, en y libérant des images qui pouvaient être enfouies. Mais Queneau qui est un expérimentateur né a dû s'échapper des limites du dogme surréaliste pour écrire ses romans. Ses recherches sont essentiellement littéraires, et comme telles, sont concernées par les problèmes de style et de forme que les surréalistes eux-mêmes ignoraient délibérément; de plus, et ce n'est pas le moindre, l'auteur accorde un rôle prépondérant au lecteur dans le processus de signification du texte.

Il n'empêche que de sa collaboration au groupe surréaliste, il reste à Raymond Queneau, même dans ses romans, tous écrits après 1932, l'utilisation du rêve et du fantastique, la banalité avec le goût de quelque chose de merveilleux, celui des voyages sans but, des rencontres surprenantes, une poésie étrange d'objets familiers, les aspects humoristiques et dérisoires de la vie quotidienne; par exemple, les altercations entre voyageurs de train de banlieue, les séries de condamnations et le ton des lettres d'injures dans son premier roman Le Chiendent où il promène ses lecteurs dans Paris, la banlieue, les fêtes foraines, illustrent partout l'agitation d'êtres obscurs plus ou moins en marge de la société. Au premier abord, les 
personnages de Queneau n'ont rien de bien remarquables: de modeste origine, dépourvus d'ambition, un peu immatures, ils vivent dans l'instant présent. Par leur naïveté, leur gentillesse, ils évoquent ces figures à la fois désarmantes et désarmées de la comédie italienne, Arlequin, Pierrot, ou les personnages du cinéma burlesque américain comme Charlot. Ils ont leurs petits bonheurs éphémères ou de légers chagrins qui ne tournent jamais en drame. D'ailleurs entre rêve et réalité, ils ne font vraiment pas la différence. En somme, ils prennent la vie comme elle vient sans se poser de grands problèmes.

Mais parce qu'il veut aller au-delà de la négation, l'auteur les pose pour eux et les leur fait vivre sans qu'ils s'en aperçoivent: le problème de l'existence (de son pourquol et de ses comment), celui du temps qui passe, ceux de la vieillesse et de la mort, ceux des mille ennuis qui guettent à chaque moment les simples et les anonymes.

Sous ses aspects nonchalants et bon enfant, Queneau reprend les grandes réalités sociales et humaines à travers une technique littéraire très étudiée, une construction de ses romans très élaborée et des connaissances très étendues. Féru de philosophie comme de mathématiques, sa curiosité encyclopédique fit de lui un directeur tout désigné pour l'Encyclopédie de la Pléiade. Derrière l'humoriste se cache un philosophe désabusé, un peu amer et pessimiste.

Grand admirateur de Gustave Flaubert (Préface à Bouvard et Pécuchet dans B.c.1. 98) avec qui il partage la même dilection ricanante pour la "bêtise" humaine, les idées reçues, les conventions de la vie en société, il l'est aussi d'Homère, "Père de toute littérature et de tout scepticisme" (B.c.l. 124) et de Hegel qu'il a étudié sous 
l'autorité de Alexandre Kojève. L'originalité repose toujours sur une connaissance de la tradition et des oeuvres anciennes, "Imiter, c'est le seul moyen de faire du nouveau et d'être à la fois à hauteur des anciens et de son époque" (V.G. 134).

Queneau a été également influencé par beaucoup d'autres et notamment par James Joyce au niveau de la forme littéraire et auquel il rend hommage tout comme à Marcel Proust (B.c.l. 225), les deux ayant su organiser les moindres détails selon une stratégie très précise, et dans l'oeuvre desquels chaque mot a le sens qu'en ont voulu les auteurs. Le Voyage au bout de la nuit de Louis Ferdinand Céline paru une année avant Le Chiendent, lui a procuré le stimulus nécessaire pour se forger un instrument à soi, le langage. Il a voulu créer des mots qui ne se trouvent dans aucun dictionnaire et qui, pourtant, correspondent seuls à ce que l'auteur veut exprimer. Comme Céline, il a voulu se débarrasser du langage de convention qui dégénère trop souvent en langage académique, en un mot "lui botter le train" (B.c.l. 56).

Queneau exalte la perpétuelle invention jaillissante du langage parlé, émotionnel et viscéral et qui relève parfois de l'argot. Il invente même de nouveaux termes, savoureux et pittoresques, ce en quoi il rappelle Rabelais. Il désarticule la syntaxe, la rapprochant du langage oral et il écrit souvent les mots tels qu'ils sont prononcés exerçant ainsi sur le lecteur, un pouvoir comique essentiellement visuel. De plus il utilise les gestes, les inarticulations, des ponctuations particulières, les mimiques pour mieux donner une présence aux personnages. Les transcriptions sont judicieusement disposées et 
amenées à leur place à l'intérieur du texte et souvent liées à des expressions aux antipodes du langage parlé, ce qui entraîne une préciosité burlesque. Selon lui, l'écriture doit procéder d'un postulat dont on explore toutes les implications, démarche qui doit quelque chose à Raymond Roussel. C'est ainsi que dans Exercices de style et qui fut son premier véritable succès, il relate dans 99 styles possibles, qui à leur tour constituent chaque fois la règle de narration, un insignifiant épisode de la vie citadine. Des titres suffisent à l'expliquer: "Précision", "Noble", "Onomatopées" etc.

Cependant jamais dans ses romans, l'auteur ne pousse ses excès à vouloir dresser des obstacles à la communication. Son but, au contraire, est de la rendre plus aisée, plus naturelle, plus vraie. Aussi un vaste public peut se délecter en lisant la majorité des romans de Queneau, et goûter un plaisir simple, grâce au pittoresque des personnages, au déroulement d'une logique aberrante mais impitoyable des situations, grâce surtout aux expressions du langage populaire. Mais sous cette apparence de laisser-aller, d'humour, de cocasserie, beaucoup de lecteurs pressentent, derrière les nombreuses parodies des grands philosophes et des canons de la littérature, l'existence d'intentions qui invitent à une analyse sur un autre plan et sous d'autres dimensions. Car en fait rien n'est caché, tout est dit et redit mais discrètement, à la fois drôlement et difficilement.

Un plaisir premier ou la compréhension immédiate est un masque qui dẻguiserait une autre vérité dissimulée et révélée en même temps. Un déguisement n'est drôle que s'il n'est pas trop aisément identifiable et si quelqu'un est là pour le découvrir. 
... car pourquoi ne demanderait-on pas un certain effort au lecteur? On lui explique toujours tout, au lecteur. Il finit par être vexé de se voir si méprisamment traité, le lecteur. (Prière d'insérer de Gueule de Pierre) 


\section{CHAPTITRE II}

\section{LE DÉFI DU LANGAGE}

Ce que je cause bien tout de même.

- Raymond Queneau,

Le Dimanche de la vie

\section{INVENTION VERBALE}

Lisant Queneau, ce qui frappe d'abord, c'est le canular, l'invention verbale, la fantaisie et l'accumulation systématique. Le début des Fleurs bleues renvoie le lecteur à l'école primaire, à l'époque des jeux de mots, pas toujours bons d'ailleurs comme le constate lui-même le duc d'Auge, ou des pauvres blagues sur les noms propres qu'on écorche ou déforme, "... de Romains fatigués, de Sarrasins de Corinthe, de Francs anciens, d'Alains seuls" (F.B. 13). Queneau pousse le canular au second degré pour révéler que les Huns se préparent des stèques (sic) tartares, les Gaulois fument des gitanes, les Sarrasins fauchent de l'avoine, les Francs cherchent des sols ... et bien sûr "les Normands buvaient du calva". Un critique, Mathieu Galley, note dans sa chronique de juin $1965^{1}$ que le récit puise dans l'Almanach Vermot des calembours "hénaurmes" mais Zazie l'avait déjà affirmé: "C'en est encore une que j'ai trouvée dans les Mémoires du général Vermot" ( $Z$. 172). Il est bien vrai que le lecteur se sent complètement désorienté 
voire désarmé devant de tels calembours. Et pourtant, les variations se font selon la linguistique de Roman Jakobson, tantôt selon le son (linceuls=Alains seuls), tantôt selon le sens (francs-sols: monnaie=sou et sol=terre, sachant que la tribu des Francs cherchaient de l'argent et aussi une terre), c'est à dire les deux axes fondamentaux selon lesquels s'organise le langage. Justification insuffisante sans doute, de telles calembredaines jouent plus probablement un rôle d'avertissement discret ferme et souriant comme à l'entrée de l'abbaye de Thélème (Gargantua de Rabelais). Il faut laisser à la porte le dogmatisme et les idées préconçues si l'on veut goûter ce qu'il y a à l'intérieur, "... tant d'histoire pour quelques calembours, pour quelques anachronismes. Je trouve cela misérable. On n'en sortira donc jamais?" (F.B. 14).

Dans le plaisir, souvent enfantin, des énumérations, l'excitation grandit au fur et à mesure que les limites semblent reculer. Dès le commencement, le duc d'Auge est décrit à travers les jeux de mots sur "battre":

... son humeur était de battre. Il ne battit point sa femme parce que défunte, mais il battit ses filles au nombre de trois; il battit des serviteurs, des servantes, des tapis, quelques fers encore chauds, la campagne, monnaie et, en fin de compte, ses flancs. (F.B. 14)

La présentation pleine de légèreté et de rapidité entraîne le lecteur dans un mouvement qui une fois lancé ne s'arrête pas aisément, malgré quelques modulations qui lui imposent un rétablissement: le lieu commun étant "Il faut battre le fer pendant qu'il est chaud." 
Queneau aime grossir et exagérer, entre sens et non-sens à la limite de l'absurde "quand l'huître a causé" (fermé comme une huître) ou encore "à poisson qui cause" (muet comme une carpe) et "... autres proverbes de vaste salaison issus du fin fond aussi faux que lorique de la sapience îlede françouèse" (F.B. 35) qui feraient rire (un peu jaune) les autoritês académiques. Queneau se moque aussi (sans méchancetẻ) de la propension invétérée et persistante de chacun à accorder crédit à tous les mots, pensant que s'ils s'accordent ainsi il doit bien y avoir une raison (et naturelle de préférence).

L'incitation à la débauche verbale est sans arrêt présente pour déplisser "la glabelle"; ainsi "le buffet genre hideux" (Z. 156) est une équivoque qui dit bien l'esthétique calamiteuse de l'inévitable buffet Henri II. Evoquant les théories astronomiques et très probablement le triste sort de Galilée, l'abbé Riphinte condamne l'hérétique doctrine de Copernic qui proposa pour la première fois d'imaginer que la terre tournait autour du soleil et non l'inverse (il est mort l'annẻe même où son ouvrage fut publiê). Esprit rebelle, le duc d'Auge commente distraitement: "Copernic soit qui mal y pense" (F.B. 151), sur le modèle de la devise de la couronne d'Angleterre.

Cependant, les plaisanteries cocasses sont moins gratuites qu'elles ne paraissent au premier abord. Ainsi, certains jeux verbaux renvoient directement à des querelles d'actualité sur la pureté de la langue française et notamment sa contamination par l'anglais. Queneau prend un malin plaisir à se moquer des puristes qui protestent contre le franglais. Voici un curieux dialogue: 
- Male bonas horas collocamus si non dicis isti puellae the reasons why this man Charles went away.

- Mon petit vieux, lui répondit Gabriel, mêle-toi de tes cipolles. She knows why and she bothers me quite a lot.

- Oh! mais s'écria Zazie, voilà maintenant que tu sais parler les langues forestières. (Z. 92)

et un autre qui demande un effort similaire pour être compris:

- Esquiouze euss, dit le campeur mâle, ma vie sind lost...

- Capito? Egarrirtes... lostes....

- Il cause bien, murmura Cidrolin, mais parle-t-il l'européen vernaculaire ou le néo-babélien? (F.B. 19)

Queneau n'avait pas attendu la condamnation du franglais pour en fabriquer dès son premier roman, Le Chiendent, dans lequel le postier s'appelle "le briffe-trégueur". Dans Zazie le métro, c'est une véritable explosion, "les bloudjinnzes", "coboille" (cow boy), "apibeursdè touillou" (happy birthday to you), "slipe-tize" et autres transcriptions cocasses et "berlitzcouliennes." "J'aurais voulu être gueurle, dit Lalix. Je danse pas mal et je suis bien balancée" (F.B. 184). Ces variations orthographiques font sourire mais pourtant elles font partie de la vie de tous les jours.

Queneau donne trois raisons à sa passion pour le français parlé. "Je pense que tout dût commencer avec des journaux comme L'Épatant avec leurs Pieds nickelés" (B.c.l. 11). Ce fut ensuite la lecture du Langage de Joseph Vendryès où ce dernier fait preuve d'une grande liberté d'esprit et même d'une audace peu conforme à l'image qu'on se fait d'un savoir académique. Queneau en relève divers passages qui ont essentiellement trait soit aux mots eux-mêmes (morphologie et orthographe), soit à leur disposition à l'intérieur de la phrase (syntaxe). Par exemple le -s de pluriel devant une voyelle devient $z$, d'où la confection de mots comme z-yeux (qui donne lui- 
même naissance au verbe zyeuter), "Vous feriez mieux d'aller garder vozouazévovos" (vos oies et vos veaux) (Z. 112). Mais à l'évidence, ce qui a le plus marqué Queneau concerne l'ordre des mots dans la phrase dont une des meilleures illustrations est l'ouverture provocatrice du Dimanche de la vie: "Il ne se doutait pas que chaque fois qu'il passait devant sa boutique, elle le regardait, la commerçante, le soldat Brû" (D.V. 15). Benveniste, dans son traité de Linguistique générale a montré que la syntaxe du français moderne se rapprochait des langues indo-européennes (il cite notamment le chinook et le takelma, langue des Indiens de l'Oregon). Les morphèmes sont regroupés dans la première partie de la phrase et les données concrètes (sémantèmes) dans la seconde. Le français parlé a tendance effectivement à rejeter à la fin l'élément sur lequel porte l'attention principale, qu'il s'agisse du mot ou du groupe de mots (Benveniste 231).

Dans Les Fleurs bleues, beaucoup de constructions de vieux français sont utilisées, telles que l'omission du pronom sujet, "Joachim me prénomme" (F.B. 13). Dans Zazie dans le métro, Queneau joue avec la grammaire et les difficultés linguistiques auxquelles est confronté Trouscaillon, "Je me vêts?... avec 'l'accent circonchose'... Je m'en vais" (Z. 160). Mais délibérément beaucoup de conventions sont violées, "Il serva, on trinquit" (P. 106). L'exemple grec est la troisième raison citée par Queneau de sa vision particulière de la langue. Ayant sejjourné en 1932 en Grèce, il découvre un pays écartelé entre deux langues, la "catharevousa" qui maintient la plupart des structures syntaxiques du grec ancien et qui n'est quasiment plus parlée et même 
incompréhensible à la très grande majorité des habitants, et le "démotique" où les déclinaisons ont disparu, les formes verbales sont simplifiées et qui est devenu la langue "naturelle". Queneau pense alors que la différence. déjà perceptible entre français êcrit et français parlé allait s'accentuer et, selon toute probabilité, le français écrit devait se scléroser en langue morte à brève échéance et donc disparaître. Queneau cite en exemple, l'anglais comme langue riche et dense ayant su constamment intégrer son parlé dans son écrit et "dans laquelle il n'y a aucune faille entre le parlé Berlitz et l'académique... malgré son orthographe lunatique" (B.c.1. 85). Mais la disparition du français écrit était un pronostic audacieux, en tout cas prématuré. D'ailleurs Queneau reconnaît, en 1969, que les théories qu'il avait soutenues à propos du néo-français n'ont pas été confirmées par les faits et d'ajouter:

...paradoxalement (ou dialectiquement), on doit en chercher la raison dans le développement des moyens de communication audio-visuels, comme on dit, qui a répandu une certaine manière (plus ou moins correcte) de parler, et qui a appris aux locuteurs à se surveiller à force de voir d'autres eux-mêmes le faire, l'habitude, nul ne l'ignore, est une seconde nature. (V.G. 222)

Le "français écrit" non seulement s'est maintenu mais s'est renforcé.

Une autre influence est attribuée à Queneau; il s'agit du Voyage au bout de la nuit de Céline. "Ici (dit-il), enfin, on a le français parlé moderne, tel qu'il est, tel qu'il existe" (B.c.1. 18). Plus qu'une reconnaissance de dette, cette phrase constitue plutôt un hommage, étant donné que le roman de Céline est parut au moment où Queneau avait presque terminé la rédaction du Chiendent. Selon Jacques Bens, 
personne ne parle suivant le style prétendu "parlé" de Céline. Il estime que "c'est une construction gratuite, synthétique, laborieuse, plus artificielle encore que la langue académique", car il juge que si celle-ci est seulement écrite, du moins l'est-elle, alors que celle-là ne se parle ni ne s'écrit ailleurs que dans les livres de Céline. "Combien ont exprimé le même souci d'un langage vivant?" (Bens 51).

Chaque jour, autour de soi, on entend parler (on parle soimême) comme le font les personnages de Queneau, avec les mêmes mots, les mêmes tournures de phrases, les mêmes processus de pensées. Les à-peu-près, les jeux homophoniques ou équivoques éthymologiques, les intrusions de mots étrangers ou les phrases interrompues et en apparence "incorrectes". La plupart des dialogues dans les romans de Queneau ont l'allure de la conversation réelle, où les phrases ne se terminent presque jamais, où les verbes manquent souvent, où l'essentiel n'est pas dit, exprimé mais sous-entendu, suggéré par la rencontre des deux ou trois personnes qui parlent. Ils arrive même que les interlocuteurs suivent chacun leur fil dans deux suites parallèles sans s'écouter, et puis tout à coup se rejoignent par une sorte de rupture logique qui correspond bien à ce qui se passe réellement, mais non à ce qui devrait se passer selon les habitudes de la fiction. En fait, cette disposition des mots, Queneau l'a utilisée non seulement dans les dialogues mais aussi dans le récit, par exemple:

Ça c'est vrai, pour une noce, ça c'est une noce. Tout le monde n'est pas de cet avis cependant; Thémistocle, par exemple, trouve que ça manque de jeunes filles, Mme Pic juge l'assistance plutôt vulgaire, et son époux espérait un menu plus copieux. Mais qui songerait à exiger que la noce d'une serveuse de bistrot de banlieue soit aussi reluisante que celle d'une prinsouesse? (C. 281) 
Tous ces passages sont là pour faire sourire mais relèvent aussi d'une conception esthéthique de la langue, arme subtile et délicate pour celui qui sait convenablement s'en servir,

D'abord, son frère Saturnin avait poussé les hauts cris: jamais d'la vie é n'irait voir Meussieu Narcense. Qu'est-ce qu'elle lui voulait? De quoiqu'é s'mêlait? Ek cétéra, ek cétéra. (C. 169)

Le résultat, selon Roland Barthes, est "de faire surgir à la place du mot pompeusement enveloppé dans sa robe orthographique, un mot nouveau, indiscret, naturel, c'est à dire barbare" (Barthes 126). Mieux encore, ces innovations ont un effet important sur le lecteur en l'obligeant à étudier de plus près le texte plutôt que de l'absorber passivement, "il (Queneau) secoue son lecteur en lui proposant périodiquement une sorte de rébus plus ou moins facile ou plus ou moins obscur" (Doppagne 92).

Dans l'alphabet, il existe une lettre caméléon, assez étrange: $\mathrm{x}$ qui sert à noter (ks) ou (gs) ou (z) ou encore (s). Par ailleurs, Monsieur Tout-le-monde est un monsieur $\mathrm{X}$ dont on peut voir éventuellement l'intérieur aux rayons X; $\mathrm{x}$ est une inconnue en algèbre et un $\mathrm{X}$ est un polytechnicien, obligé de conclure que tout $\mathrm{X}$ est suspect. Queneau semble avoir quelque réticence à écrire cette lettre: "claquesons", "espliquerai", "egzeguta", "esploitent" ou encore "esplications" parcourent les diverses possibilités de prononciation, particulièrement dans Zazie dans le métro où l'auteur se moque gentiment de la langue familière. Mais ce jeu du " $x$ " montre aussi que Queneau ordonne son univers à partir du langage; il le transforme et transforme par là même son rapport avec le monde. Les variations sur 
l'existence, selon le sens qu'elles prennent au fil de Saint-Glinglin. évoquent toutes les valeurs d'une existence sceptique: "ogressence" (ogresse), "âcresistence" (âcreté), "aigresistence" (aigreur) et même "hainesistence" (haine) de la vie. "Quelle colique que l'egzistence", soupire Mado P'tis-pieds dans un moment de mélancolie avant qu'elle n'accepte le "marida" que lui a proposé Charles (Z. 145). L'auteur va encore un peu plus loin dans l'orthographe traditionnelle. En écrivant dans Les Fleurs bleues, les chous, les hibous, les chevals et les chevaus, il semble prendre sa revanche sur la tyrannie des instituteurs; mais il s'agit d'un roman historique et "x" $y$ ponctue l'évolution de la langue. Or -1 devient - $u$ devant $-\mathrm{s}$ justement au XIIIe siècle; us est noté $\mathrm{x}$, puis on oublie que le $\mathrm{x}$ comprend le $\mathrm{u}$ et on le réintroduit (ux), ce qui revient en fait à écrire u.us, ce qui est absurde. Queneau fait semblant de prendre des libertés avec l'orthographe alors qu'il suit fidèlement ce qu'il doit trouver dans les traités de phonétique. Sur le même modèle, archaïsmes et néologismes émaillent ce même roman. Beaucoup de termes de la langue médiévale et des références à Rabelais donnent au récit un petit air ancien mais souvent obscur: "Tu aurais donc ici un gallimard et un parchemin" (F.B. 109) est un écho de "gualimart" dans Gargantua, sachant aussi que Gallimard est l'éditeur de Queneau. Par contagion, le néologisme gagne même les chevaux Stèphe et Sthène, qui s'ennuient en voyage et entreprennent le dialogue suivant:

- Tu souffres très exactement de nostalgie, dit Stèphe.

- Nostalgie? dit Stène, voilà un mot que je ne connais pas.

- Il est d'invention récente, dit Stèphe d'un ton doctoral.

Il vient de nostos et d'algos, algos qui veut dire en grec 
souffrance et nostos qui dans la même langue veut dire retour.

- Et toi, dit Sthène, tu es atteint de logorrhée.

- Logorrhée, dit Stèphe, voilà un mot que je ne connais pas.

- Je pense bien, dit Sthène, je viens de l'inventer. (F.B. 189)

Or "nostalgie" est apparu en 1759 (la scène se passe en 1789) alors que logorrhée est daté de 1839. Les chevaux parlent comme des livres et tout cela ne serait qu'érudition si Queneau ne prenait pas la peine d'utiliser les guillemets qui établissent la distance nécessaire pour en sourire.

Même si, selon Queneau, "la plus phonétique (des orthographes) semblerait s'imposer", il sait pertinemment qu'un texte ainsi transcrit serait indéchiffrable: "Mézalor, mézalor keskon nobtin!... écrit-il en 1937 (B.c.l. 22). Dans Zazie le métro, le plus contaminé des textes en prose, la graphie phonétique est cependant discrète et se limite à quelques formules bien connues telles que le tout premier mot du livre, "Doukipudonktan" ou "Lagoçamilébou" (La gosse a mis les bouts). La tendance agglutinative est une autre caractéristique du français parlé et qui en rend la compréhension souvent difficile pour les étrangers. L'illustration la plus nette apparaît dans Le Chiendent à l'instant où deux personnages se reconnaissent: "bonjourmeussieucommentçavacematinpasmaletvousmêmelefondel'aire stfraismaistoutàlheureilferachaud" (C. 38). Les Fleurs bleues, le dernier roman, est encore truffé de dysorthographies cocasses mais non systématiques et qui sont là de toute évidence pour faire rire mais non pas pour réformer la langue française; ni "les céhéresses" (C.R.S.), ni les "houatures", ni les "achélèmes" (H.L.M.) n'engendrent la 
mélancolie pas plus que les "stèques" ou "Stèfstu esténoci" (Stèphe se tut et Sthène aussi) (F.B. 102) faisant écho à "Ltipstu (Le type se tut) et Zazie reprit son discours" (Z. 54).

Si Queneau utilise l'humour c'est sans doute pour gratter le monde apparent, pour y trouver une vérité sous jacente, pour montrer la vanité, la sottise, l'absurdité et c'est bien normal qu'il dirige cet humour vers ce qui lui tient particulièrement à coeur, c'est-à-dire le langage lui-même et le style. Le langage que chacun utilise chaque jour est rempli de formules absurdes, d'expressions détournées de leur sens primittif, d'idiotismes, de lieux communs, de platitudes et de clichés du genre: "Ce n'est pas seulement le physique qui compte, c'est le moral" répond Chantal quand on lui demande son avis sur les attraits physiques de sa soeur (D.V. 14). Parce que chacun y est habitué, personne n'y prend garde; mais ll suffit de les écrire un peu différemment, de les décortiquer ou de les pousser à bout pour que leur absurdité saute aux yeux. Ainsi lorsque Queneau écrit:

Il commença par employer exclamativement la deuxième personne du singulier de l'impératif présent du verbe tenir, puis énonça les syllabes composant le nom de la personne reconnue par lui. (C. 129)

Le mécanisme de l'humour agit en deux temps; l'auteur utilise une bien longue périphrase qui d'ordinaire ne nécessite que deux mots, puis on constate qu'il n'y a aucune raison de s'écrier par exemple "Tiens, Jules!" quand on rencontre Jules: pourquol "tiens"? Tiens quoi? Les exemples sont si nombreux qu'il suffit d'ouvrir un livre de Queneau pour les découvrir. Le langage oral comprend, outre les mots plus ou moins bien organisés en phrase, un nombre 
incroyable de grognements, raclements de gorge, grommellements, interjections, "les sons, les bruits, tout ce qui entre par l'oreille" (D.V. 176), qui participent à la communication et qui ont une valeur sémantique,

- Vdvé houhouh iage? demande Mme Cloche, la bouche pleine.

- Comment?

- Vous d'vez êt' souvent en voyage, que j'dis. (C. 277)

Jean Queval, un critique, pense que la langue s'est épurée de livre en livre ${ }^{1}$. Plus exactement, Queneau ajuste le style à son sujet, celui qui le racontera le mieux. En tout cas, même si le style est divers, la vision et l'écriture apparaissent comme deux éléments juxtaposés, et l'écriture se met au service de la vision comme au cinéma. Si l'image peut montrer deux évènements simultanés, le discours doit les raconter l'un après l'autre et pourtant Queneau a relevé ce défi comme l'illustre la conversation suivante entre Cidrolin et le passant dans Les Fleurs bleues:

- Vous êtes de ces nomades...? demanda Cidrolin poliment.

- Moi? point. J'habite l'hôtel...

- et moi cette péniche...

- un hôtel de luxe même...

- immobile...

- il y a des vatères dans la salle de bains...

- amarrée...

- l'ascenseur...

- je pourrais même avoir le téléphone...

- le téléphone dans les chambres...

[- etc....] (F.B. 30) 
La structure de ce passage figure celle du livre faite de parallélismes, de rimes et de résonnances. Auge et Cidrolin suivent chacun leur propre idée: il y a juxtaposition sans interpénétration.

Roland Barthes insiste sur le fait que Queneau, bien qu'il attaque constamment les conventions littéraires, demeure cependant et paradoxalement dans ses limites:

Toutes les écritures y passent: l'épique... l'homérique... la latine... la médiévale... la psychologie... la narrative... l'expression est ici légère, elle désarticule en passant, ce n'est qu'une écaille que l'on fait sauter à la vieille peau littéraire; c'est une parodie minée de l'intérieur, recélant dans sa structure même une incongruité scandaleuse. (Barthes 126)

L'illustration la plus brillante est sans doute réalisée dans Exercices de style que des critiques de l'époque avaient vus comme une tentative de démolition de la littérature, alors que Queneau voulait "décaper la littérature de ses rouilles diverses, de ses croûtes... sans ennuyer trop le lecteur" (B.c.1. 43). Pour renforcer la parodie des styles établis, Queneau se plaît au télescopage des usages littéraires et des approximations de ce qui est appelé justement le style "populo"; ce jeu consiste à insérer dans un dialogue le français écrit et le français oral, témoin l'incartade lancée à l'adresse de Gabriel:

Le ptit type se mit à craindre. C'était le temps pour lui, c'était le moment de se forger quelque bouclier verbal. Le premier qu'il trouva fut un alexandrin:

- D'abord, je vous permets pas de me tutoyer. (Z. 10)

Un autre exemple dans le même livre et qui va au-delà de l'effet, de la dérision, est ce banal échange dans un français châtié entre un "kidan" et Trouscaillon dans son uniforme de "flicmane" lequel, à l'évidence, éprouve bien des difficultés avec la grammaire: 
- M'autorisez-vous donc à de nouveau formuler la proposition interrogative qu'il $y$ a quelques instants j'énonça devant vous?

- J'énonçai, dit l'obscur.

- J'énonçais, dit Trouscaillon.

- J'énonçai sans esse.

- Ah! la grammaire c'est pas mon fort. Et c'est ça qui m'en a joué des tours. Passons. (Z. 163)

Valentin, dans Le Dimanche de la vie rappelle clairement à son lecteur que tout style littéraire, tout comme les mots ou la phrase, est absolument gratuit, assurant une certaine fonction dans un contexte donné mais néanmoins parfaitement superflu. Quand on lui demande de décrire une des clientes de sa boutique, il réplique simplement dans ces termes:

$\mathrm{Hm}$ très bien. Valentin se méfiait des descriptions trop lyriques; sinon il aurait dit: une chouette mouquère un peu mûre avec un balcon aux pommes. (D.V. 137)

Entrent aussi dans l'usage pseudo-littéraire, le trop fameux biendire, ces métaphores devenues clichés que l'accumulation suffit à ridiculiser, comme l'illustre la description suivante du fakir CrouiaBey:

Il a des yeux de braise, un front de penseur, des mains de pianiste, une taille de guêpe, une barbe de sapeur, des lèvres de corail, un thorax de taureau, ah! qu'il est beau, ah! qu'il est beau! (P. 31)

Mais c'est pas leur intervention discrète, comme l'épice qui relève subtilement le goût de la sauce, que les opérations de langage accusent le contraste entre français et néofrancais. Avec Queneau, la réussite vient d'un sens très sûr de la mesure qui lui fait changer de ton dès l'instant précis où une sorte de style pourrait devenir 
monotone, insistante et lourde, et c'est la variété qui préserve la légèreté de l'ensemble.

\section{CODE DE L'ÉCRITURE}

Bien que Queneau soit avant tout concerné par le langage, il est conscient que ce n'est qu'un code arbitraire parmi d'autres, et qu'aucune déclaration ne peut être formulée d'une façon adéquate. "Pourquoi qu'on dit des choses et pas d'autres? demande Zazie... on est tout de même pas forcé de dire tout ce qu'on dit, on pourrait dire autre chose" (Z. 27-28). Personne ne la contredit. Le langage est donc condamné à être un instrument imparfait et n'est qu'une approximation de ce qu'il désigne. Comme leur créateur, les personnages sans arrêt s'interrogent sur les mots qu'ils utilisent, témoin cette réflexion de Paul Brétouillat dans Le Dimanche de la vie:

(Il) envisagea pendant quelques instants d'orienter la controverse vers les questions philologiques. Il n'admettait pas que l'on employât les mots dans des acceptations inexactes et il lui avait fallu une grande force de volonté pour se retenir de critiquer l'utilisation constante que faisait sa belle-soeur du verbe causer au lieu de son cousin parler. (D.V. 52)

Queneau reste conscient dans ses oeuvres de la réflexion sur l'écriture elle-même. Gens simples mais toujours vrais, les personnages des romans ne se rendent pas toujours compte du double jeu auquel ils prennent part lorsqu'ils racontent leurs propres histoires de bons Français frondeurs en proie au tourment de la vie citadine. Pour eux, les mots sont juste des mots, bien que des fois ils s'interrogent: "On sait des mots mais on ignore complètement de quoi 
il s'agit" remarque Zazie, "les mots n'ont plus le même sens qu'autrefois" insiste le flicmane Trouscaillon (Z. 105). Ils sont souvent des marionnettes dont l'auteur (et avec lui les linguistes) tirent les ficelles en leur faisant jouer une autre histoire, celle du langage et des mots, histoire commencée par Ferdinand de Saussure avec la naissance du signe linguistique et son exploitation. Ce double jeu n'est nulle part plus apparent que dans "La Mort du cygne" que Gabriel danse tous les soirs pour la marionnette Gabriel(la) qui, elle, danse la mort du Signe.

Les mots peuvent acquérir en effet une signification complètement arbitraire. Une dispute, dans Les Fleurs bleues, illustre clairement cette affirmation, quand un promeneur fait la leçon à Cidrolin sur la pêche à la ligne:

- Ce sont des maniaques sadiques, les pêcheurs à la ligne... Franchement, ne trouvez-vous pas l'hameçon plus sournois et vicieusement barbare que l'espadrille?

- L'espadrille?

- Ces trucs qu'ils enfoncent dans le cou du fauve.

- Vous êtes sûr que cela s'appelle comme ça?

- Pour le moment, moi j'appelle ça comme ça, donc ça s'appelle comme ça et comme c'est avec moi que vous causez en ce moment et avec nul autre, il vous faut bien prendre mes mots à leur valeur faciale. (F.B. 30-31)

Détachés de tout contexte, les mots peuvent aussi être là comme objets de contemplation. Dans Le Chiendent, Etienne Marcel devient fasciné par l'enseigne d'un café, visible du train, et il s'inquiète de savoir si "FRITES" n'est pas un nom de personne et sourit en pensant à "Meussieu Frites". Cette expérience apparemment anodine est décisive dans la prise de conscience d'Etienne du langage; d'ailleurs plus tard au cours d'une conversation, il en tire la conclusion suivante: 
Les mots sont aussi des objets fabriqués. On peut les envisager indépendamment de leur sens.

Etienne venait de découvrir ça, en le disant. Il se le répéta pour lui-même, et s'approuva; ça, c'était une idée.

- En dehors de leur sens, ils peuvent dire tout autre chose. Ainsi le mot "théière" designe cet objet, mais je puis le considérer en dehors de cette signification, de même que la théière elle-même, je puis la regarder en dehors de son sens pratique.... (C. 186)

En renversant la relation acceptée entre signifiant et signifié, dans certains cas, les mots prennent un sens inattendu qui néanmoins dérive de leur forme. Par exemple dans Le Vol d'Icare, les deux sens du mot vol theft et flight jouent sur la dichotomie à l'intérieur du texte (ce double sens sera repris par Hélène Cixous). Dans d'autres cas, les mots existent en dehors de toute signification, ne dénotant rien et ne dérivant leur valeur que par leur présence sur la page écrite, en somme n'ayant aucune relation avec leur référent. Fédor Balonovitch, dans Zazie dans le métro, persuade un groupe de visiteurs étrangers que le Tribunal de Commerce est réellement la Sainte Chapelle, lesquels n'ont aucun moyen de faire la différence; ils sortent en effet avec enthousiasme leur monnaie, impressionnés par l'amplitude des connaissances linguistiques de leur "archiguide", qui par ailleurs, connaissait "à fond la langue française, étant natif de BoisColombes. (Z. 123)

Très souvent également, le langage se révèle impuissant entre individus; deux personnages échangent des banalités:

- Vos parents vont bien?

- Oh oui très bien. Et les vôtres?

jusqu'à ce qu'ils réalisent la futilité de leur conversation. Ils se regardent. Ils entrevoient très légèrement la connerie du langage humain. (D.V. 118) 
D'une façon générale, tous les personnages de Queneau sont des parleurs intarissables, utilisant largement la répétition qui est un véritable tic de langage ou de bégaiement. A.J. Greimas établit un contraste entre les deux extrêmes de la non-communication: la liberté incontrôlée du schizophrène et la parole totalement socialisée, itérative (Greimas 36). Le fameux refrain: "Tu causes, tu causes, c'est tout ce que tu sais faire" du perroquet Laverdure dans Zazie dans le métro ou le "Pra-pra-pra... Cuterie-cuterie... de Jean-Sans-Tête dans Le Dimanche de la vie illustrent parfaitement la négation de la communication, privée d'information. Il semble dans ce cas que le langage, chez Queneau, oscille entre deux extrêmes: celui conscient de ses failles et qui ne cesse de se remettre en cause et celui où la parole est vidée de tout sens.

Mais Queneau ne s'intéresse pas seulement aux façons de parler. On pense avec des mots. Attaquer le langage, c'est viser la pensée et au-delà du verbe, la pensée ou l'absence de pensée, évidemment. C'est aussi s'en prendre aux façons de vivre. L'humour qui s'exerce aux dépens des personnages dépasse le simple comique de situation et s'élève à un humour au deuxième degré comme l'a expliqué Henri Bergson: il s'agit de décrire méticuleusement ce qui est, en affectant de croire que c'est bien là ce que les choses devraient être, descendre de plus en plus bas à l'intérieur du mal pour en noter les particularités avec une froide indifférence, et pour ce faire l'auteur affectionne les termes concrets, les détails et les faits précis. Grâce à son humour, il démonte le monde pour en montrer la vanité, la sottise, l'absurdité et subtilement révèle les non-sens et les incompatibilités dans ce qui 
paraît normal à tous en vertu de l'habitude. Dénoncer certaines façons de parler, de penser, de vivre, c'est dénoncer certaines conceptions de la vie, donc certaines philosophies. L' humour, c'est dire une chose pour en faire entendre une autre ou pour faire entendre d'une manière ingénieuse ce qu'on ne dit pas ou ce qu'on ne dit que d'une façon détournée. L'humour est toujours discret et mesuré mais il peut devenir une arme puissante qui montre et démontre. 


\section{CHAPITRE III}

\section{LA SYMBOLIQUE STRUCTURELLE}

Quand j'énonce une assertion, je m'aperçois tout de suite que l'assertion contraire est à peu près aussi intéressante, à un point où cela devient presque superstitleux chez moi.

- Raymond Queneau, Entretiens avec Georges Charbonnier

NOMBRES ET FORME

Les jeux de langage se rencontrent d'ordinaire en poésie, et moins souvent dans les romans, sauf à la période récente de la littérature, après Queneau. Pour ce dernier, la distinction entre roman et poésie n'a pas grand sens puisqu'il avait écrit son autobiographie en vers. Il affirme: "J'ai même écrit un roman en vers, Chêne et Chien, et j'ai choisi pour cela un sujet qui passe généralement pour ne pas être spécialement poétique, la psychanalyse" (B.c.1. 43). Dans Technique du roman (B.c.l. 27), il s'insurge contre le fait que le roman, depuis qu'il existe ait échappé à toute loi, contrairement à la poésie et d'ajouter, dans une conversation avec Georges Ribemont-Dessaignes, à propos du Chiendent: "Je me suis fixé des règles aussi strictes que celles du sonnet. Les personnages n'apparaissent pas et ne disparaissent pas au hasard, de même les lieux, les différents modes d'expression" (B.c.l. 42). Il donnait ainsi, dès son premier roman publié, l'indication d'une 
architecture très précisément calculée. La contrainte imposée n'engendre pas seulement un type de phrase, mais aussi et surtout un agencement d'ensemble des éléments. Cet agencement doit accomplir une forme calculée d'harmonie, comme une distribution arithmétique, réglée par une progression numérique qui organise les places où doivent figurer tel ou tel élément. On sait le goût prononcé de Queneau pour les mathématiques, le héros d'Odile passe ses journées à explorer "le monde des réalités mathématiques... douces ténèbres ouatées de signes majuscules et d'indices variés." Un des derniers écrits de Queneau, Les Fondements de la littérature, tente de dégager les postulats et axiomes, théorèmes et corollaires, qui pourraient concourir à une formalisation des diverses possibilités (et impossibilités) narratives. Michel Leiris s'est demandé si c'est de ce goût que provient l'attention que Gueneau porte à son désir d'écrire une oeuvre au moyen de variations proliférant presque à l'infini autour d'un thème assez mince ${ }^{1}$. D'où l'image de Claude Simonnet qui compare notamment Le Chiendent à "un bulbe d'oignon aux couches successives dont les uns se contentent d'enlever la couche superficielle tandis que d'autres, moins nombreux l'épluchent pellicule par pellicule" image qu'il avoue avoir empruntée à Queneau lui-même (Simonnet 12). La formule, aussi provocante soit-elle, doit pouvoir s'appliquer à la majorité des romans de Queneau. Qui plus est, ceux-là n'ont pas un mais plusieurs centres ou plus exactement le centre est partout et c'est sans doute la raison pour laquelle ils sont si difficiles 
voir impossibles à résumer. L'auteur lui-même avait averti ses lecteurs qu'il offrait pâture à chacun selon ses aptitudes et ses inclinations:

Toute oeuvre demande à être brisée pour être sentie et comprise, toute oeuvre présente une résistance au lecteur ... il doit y avoir effort, du moins vers le plus. Pour suivre l'oiseau dans son vol, il faut lever les yeux: ce qui peut être fatigant lorsqu'on a l'habitude de les garder baissés. Mais une oeuvre ne doit pas être difficile par simple provocation: pour suivre l'oiseau dans son vol, il faut l'avoir vu s'envoler... Ainsi Ulysse se lit comme un roman; ensuite on va au-delà. (V.G. 141)

Queneau expose clairement la structure combinatoire de certains de ses romans. Parlant du Chiendent, il précise: "Il m'a été insupportable de laisser au hasard le soin de fixer le nombre des chapitres" (B.c.l. 29). C'est ainsi que ce roman se compose de 91 (7x13) sections, 91 étant la somme des treize premiers nombres et sa somme étant 1; Zazie dans le métro comporte 19 chapitres, Le Dimanche de la vie et Les Fleurs bleues, 21. Ce dernier se déroule sur sept siècles et la péniche de Cidrolin porte le nombre vingt et un. Les noms de beaucoup de personnages de Pierrot mon ami commencent par "m", treizième lettre de l'alphabet; de plus, Mounnezergues et les frères Mouilleminche ont des noms de 13 lettres, le même nombre que le titre du roman, qui contient 9 chapitres avec l'épilogue. Plus qu'une théorie des nombres premiers, c'est plutôt d'une "symbolique chiffree" dont il s'agit; en effet, Queneau, toujours en parlant du Chiendent, voyait dans 1 le nombre de la mort des êtres et de leur retour à l'existence. Encore selon lui, 13 était un nombre bénéfique parce qu'il niait le bonheur, 7 était l'image numérique de lui-même, puisque son nom et ses deux prénoms se composaient chacun de sept lettres et qu'il était né un 21. La période couverte par l'action dans le 
premier chapitre du Chiendent est exactement de sept jours, durée pendant laquelle les sept personnages principaux sont présentés, lesquels réapparaissent dans la section finale et sept évènements inattendus ont lieu entre les personnages pris deux à deux.

Cependant, la symbolique dépasse les chiffres pour atteindre les formes. Valentin Brû, soldat au début du Dimanche de la vie, soldat se retrouve à la fin. Son beau-frère change de nom toutes les fois que l'on parle de lui, mais s'appelle Bolucra la première et la dernière. "La silhouette d'un homme se profila; simultanément des milliers. Il y en avait bien des milliers." Ainsi commence, ainsi s'achève Le Chiendent, roman exemplaire de circularité. A l'intérieur du texte lui-même, de fréquentes allusions sont faites à un retour au point de départ et à l'abolition du temps: "Qu'ils soient brûlés et qu'ils renaissent de leurs cendres," déclare Saturnin (C. 408), et dans la partie finale, les survivants de la guerre des Gaulois et des Etrusques veulent "éponger le temps et r'mettre ça" (C. 431). Pierrot, après une série d'aventures inextricables, se retrouve à la fin pas plus avancé qu'au début et donne l'impression de n'avoir réussi qu'à tourner en rond: "C'était un des épisodes de sa vie les plus ronds, les plus complets, les plus autonomes" (P. 174). Dans Saint-Glinglin, le beau temps continu que la Ville Natale apprécie au début se transforme en pluie incessante qui coïncide, parallèlement, aux influences étrangères, puis revient enfin et la ville reprend, sans histoire, sa vie. Le cycle des Derniers Jours n'est plus que saisonnier pendant les trois années estudiantines du héros Vincent Tuquedenne à Paris jusqu'au moment du dénouement où les personnages principaux disparaissent. Alors le cercle se brise 
dans une catastrophe, ce que le personnage central, Alfred, explique dans le dernier chapitre.

Attendu qu'il s'achève sur le constat d'un temps écoulé, Zazie dans le métro peut passer pour un roman plus linéaire. A la question de sa mère: "Alors, qu'est-ce que tu as fait?", laconiquement, Zazie répond: "J'ai vieilli" ( $Z$. 189). Pourtant, la scène se passe à la gare d'Austerlitz, rime de situation par identité de lieu, les premières pages du roman s'ouvrant sur les odeurs nauséabondes de la même gare. Ainsi les unités du thêâtre classique, lieu, temps, action, sont respectées. La construction suggère une oeuvre circulaire. Mais la rime finale est décalée; du quai de gare, on passe au compartiment de train dans lequel Jeanne Lalochère "fit monter" sa fille. Parlant d' Odile et Un rude hiver, Alain Calame avait constaté que "ces romans linéaires présentent dans une première partie une structure circulaire que les héros parviennent à briser, à transformer en structure linéaire" (Calame 266). Effectivement, dans Odile, le narrateur vit en reclus. Absorbé par la recherche mathématique, il connaît "une quiétude désespérée." Et voici que la femme fait irruption dans cette existence. Alors le narrateur peut constater: "Je m'étais engagé dans le monde et sorti de mon anéantissement, je distinguais les êtres comme tout homme ordinaire." Comme lui, Cidrolin, dans Les Fleurs bleues, végète dans l'espace douillet et clos de sa péniche. Ses activités l'enferment dans la circularité d'avant l'invention du temps: dormir, rêver, se rẻveiller, peindre, effacer, dormir, rêver etc. jusqu'à ce qu'intervienne Lalix, la femme. C'est à la femme qu'il appartient de faciliter l'inversion ou de la provoquer, autrement dit, "d'opérer le 
passage du cercle à la droite, de donner naissance au héros" (Calame 266). Si le cercle et la droite sont inconciliables dans le plan, ils cessent de l'être dans l'espace. Or le mouvement hélicoïdal est celuilà même que proposait Queneau pour la construction de Gueule de Pierre, incitant son lecteur à changer d'espace (B.c.1. 29): le signal final du Zodiaque, les Poissons, ne se situe pas sur le même plan que les harengs du début qui méditent sur leur sort.

Outre le symbole du temps comme succession continue sans commencement ni fin, le cercle est aussi le signe de l'unité et le développement de son point central. Tous les points se retrouvent en son centre d'où part le mouvement de l"un" vers le multiple, de l'intérieur vers l'extérieur, du non manifersté au manifesté, de l'éternel au temporel, et où se rejoignent tous les processus de retour et de convergence dans leur recherche de l'unité. C'est l'harmonie, l'unification des contraires, la résolution des oppositions.

Le thème commun aux oeuvres "parfaitement circulaires" pourrait être la crise, individuelle ou collective et la manière dont elle n'est pas résolue. En effet les personnages ne réussissent pas à s'en sortir; ils échouent, ils sont malheureux. Ils parcourent un cercle infernal et se retrouvent à la fin dans la même situation qu'au début, sans même l'expérience. Eternel retour que Queneau ne concevait alors "que comme la perpétuité irrésolue du malheur sans espoir" (vision pessimiste de Queneau). Dans une conversation avec G. Ribemont-Dessaignes, Queneau parle de ses autres romans à structure moins rigide et dans lesquels les personnages évoluent; même si la situation est apparemmment la même à la fin du livre, eux ne sont 
plus exactement semblables à ce qu'ils étaient au début de l'histoire; ils ont acquis une sorte de sagesse ou trouvé une solution à leurs problèmes et éventuellement réussi: l'homme ne fuit plus le monde, il le supporte (vision plus optimiste de Gueneau). Paul Gayot parle de ces romans comme "ouverts sur un au-delà", et il note que dans ces romans ouverts, les personnages n'en sont même plus à résoudre des problèmes, ils savent. Il leur reste à découvrir: Pierrot une chapelle, Zazie une ville, Valentin l'avenir, Cidrolin le passé (Gayot 69).

\section{ÉCHOS ET SYMÉTRIES}

Les symétries, les pendants, les points homologues nés de la structure circulaire augmentent la rigueur de l'oeuvre et lui donne une grande unité du début jusqu'à la fin. Des échanges s'opèrent, des harmonies se forment, des correspondances innombrables s'établissent entre thèmes, situations et personnages: "On peut faire rimer des situations ou des personnages comme on fait rimer des mots, on peut même se contenter d'allitérations" déclare Queneau (B.c.l. 42). Pas plus que le reste, la répartition des personnages n'est laissée au hasard. Simonnet s'étend longuement sur la figure du double dans Le Chiendent: Etienne est lié à Pierre Le Grand en vertu de leur apparence simultanée, de leur itinéraire au cours de l'histoire et de leur "alliance" pour découvrir le soi-disant trésor du père Taupe. De la même facon, Etienne forme une paire avec Saturnin à la fin du roman quand ils s'opposent à Mme Cloche transformée en "reine des Etrusques". Plus généralement, il semble que Queneau fasse se mouvoir les personnages non pas selon leurs instincts mais plutôt 
selon un mouvement déterminé, d'entrée et de sortie. Par exemple, Etienne Marcel apparaît et est effacé, au sens propre du mot, aux premier et dernier chapitres, tandis que Bébé Toutout, personnage secondaire fait son entrée au deuxième chapitre et sort du roman à l'avant dernier chapitre. Souvent aussi, Queneau rassemble toutes les figures importantes en fin d'histoire, comme dans Zazie dans le métro où tout le monde se retrouve "Aux Nyctalopes". Les quatre personnages principaux du Dimanche de la vie sont rassemblés, à la fin, dans la gare de Toulouse, Julia, sa soeur Chantal, son beau-frère Paul et son mari Valentin.

Mais un système de nombres et de rimes risque de rester abstrait et artificiel s'il ne correspond pas à un sens. Queneau met le lecteur sur la voie en donnant éventuellement des indications. Par exemple, en préface des Fleurs bleues, il rappelle l'apologue chinois:

Tchouang-tseu rêve qu'il est papillon, mais n'est-ce point le papillon qui rêve qu'il est Tchouang-tseu? De même dans ce roman est-ce le duc d'Auge qui rêve qu'il est Cidrolin ou Cidrolin qui rêve qu'il est le duc d'Auge? (F.B. 7)

Le principe de la répétition incarné dans le dédoublement donne naissance aux deux personnages principaux du roman. Les évènements du récit se déroulent dans deux univers différents, dans deux temps différents, l'un qui semble fictif, l'autre réaliste. Dans ces deux mondes vivent des personnages qui se font écho, soit par les caractéristiques soit par les noms. De plus, la rencontre des deux héros va donner naissance à un jeu de miroir,

- Maintenant que nous nous connaissons, appelez-moi tout simplement Joachim.

- Et pourquoi vous appellerais-je Joachim? 
- Parce que c'est mon prénom.

- C'est aussi le mien, dit Cidrolin. Je ne me vois pas m'appelant sous les espèces d'un autre!

- Espèce d'autre vous-même, répliqua le duc avec bonhommie. (F.B. 255-256)

La concordance est telle qu'elle menace les identités et pourtant chacune est nettement marquée, ce sont même surtout les différences qui sont soulignées (Calame 17). Les deux personnages vivent des évènements parallèles même si la ressemblance des actes tient parfois à de l'à-peu-près. L'un et l'autre se déplacent sous de faux noms qui sont des anagrammes. L'alternance systématique des deux "mondes" offre au moins deux possibilités d'agencement. Soit une rime relie un élément "Auge" à un élément "Cidrolin", et on insiste alors sur le parallélisme des deux mondes, suggérant par là que l'un (mais lequel?) est le rêve de l'autre, par exemple Auge a toujours rêvé, dit-il, d'habiter sur une péniche, péniche sur laquelle habite en effet (?) Cidrolin, qui de son côté rêve les aventures que vit en effet (?) Auge; chacun l'interprète différemment. Il y a donc rupture puis continuité, ce qui provoque parfois un mouvement instinctif d'étonnement: "Cidrolin sursauta" (F.B. 164), comme lorsqu'on s'éveille sans avoir encore conscience qu'on s'était assoupi, puis le train-train usuel reprend son cours. La transition s'est faite par l'intermédiaire d'un bûcheron qui demande à Auge des nouvelles de sa fille Lalix qui racontait qu'elle était fille de bûcheron, établissant ainsi un passage continu d'un monde Cidrolin à la "réalité" du jour.

La ressemblance des deux mondes, celui du réel et celui du rêve, est ainsi soulignée. Les nombreuses reprises tout au long du roman donnent le sentiment que les évènements historiques se 
répètent sans véritable progression, que c'est toujours la même chose qui se produit et que le temps, comme on dit "tourne en rond." La structure cyclique des Fleurs bleues entre en concurrence avec la disposition linéaire qui a été évoquée au début de ce chapitre. Effectivement, tandis que Cidrolin fait ses siestes durant l'automne 1964. Auge se promène à travers l'histoire en commençant par sa rencontre avec Saint Louis en 1264. Un intervalle de cent soixante quinze ans sépare chacune de ses apparitions jusqu'en 1964 où il retrouve Cidrolin qu'il a vu dans ses songes. Des éléments réalistes (évènements, décors et personnages réels) sont respectés et soigneusement répartis, cinq chapitres par époque, ce qui devrait produire vingt cinq chapitres, mais avec les transitions au milieu de quatre chapitres, et la logique parfois difficile à admettre des problèmes d'intervalles, le nombre des chapitres est bien ramené à 21. Une sorte de fiction historique est respectée; la première phrase du texte est à cet égard tout à fait symptomatique, date, lieu, héros, tout y est: "Le vingt cinq septembre douze cent soixante quatre, au petit jour, le duc d'Auge se pointa sur le sommet du donjon de son château..." (F.B. 13). Cela signifie aussi que selon la règle du parallélisme des deux modes, des évènements sont en quelque sorte programmés à l'avance.

Pourtant cette règle de composition est ébranlée de deux façons: d'abord par les anachronismes qui interviennent dans les deux directions narratives: Auge rêve de la péniche et de "houatures" (d'une série à l'autre), Russule chante la Carmagnole en 1439 (même série), d'ailleurs Auge lui-même avait déjà annoncé: "Si les Capets 
commencent à nous traiter de la sorte, on verra bientôt les aristocrates à la lanterne" (F.B. 57). Les anticipations prennent toutes les formes imaginables et rappellent ainsi le principe du roman classique où le narrateur fait semblant de ne pas savoir la fin de l'histoire qu'il connait pourtant pertinemment. D'autre part, Queneau prend soin de ne pas marquer trop nettement le passage d'une époque à une autre, provoquant l'hésitation du lecteur qui, par exemple ne sait pas très bien en quelle année situer tel ou tel évènement historique, année révélée par un indice plusieurs pages plus loin. Ce brouillage est accentué par la longévité des héros qui "vieillissent" de cent soixante quinze ans à chaque bond et paraissent à la fois identiques à eux-mêmes et pourtant légèrement modifiés: Auge redevient veuf sans que cela paraisse le changer beaucoup. De ce fait une confusion est introduite dans laquelle le temps est pratiquement escamoté bien qu'une évolution soit néanmoins marquée et que la continuation semble dominer. La persistance, plutôt que la permanence des mêmes personnages donne le sentiment qu'ils assistent en spectateurs au déroulement de l'histoire plus qu'ils ne participent en acteurs aux évènements. Il semble qu'il $y$ ait une antinomie fondamentale où coexistent en parallèle deux systèmes de narration: celui de la "réalité" (histoire) et celui de la fiction (roman). C'est justement en mêlant les deux ou plus exactement en les faisant jouer l'une contre l'autre que Queneau donne au roman une structure dynamique; il oblige par là même son lecteur à une incessante activité d'interprétation. C'est effectivement ce que laissait entendre le 
prière d'insérer du roman: "Tout comme dans un vrai roman policier, on découvrira qui est cet inconnu..." (F.B. 7).

Le mystère est très présent aussi dans pierrot mon ami: l'incendie de l'Uni-Park est-il accidentel ou allumé par Crouïa-Bey sur l'ordre de son frère Jojo Mouilleminche alias Voussois? Mort imaginaire de Jojo et mort réelle d'un prince poldève où s'est édifié l'Uni-Park et le Jardin Zoophilique? L'imagination de Zazie est particulièrement fertile. Peut-on la croire quand elle raconte à Pédrosurplus, avec des détails aussi croustillants et sans émotion apparente le meurtre de son père? (Z. 54). En tout cas, elle bouleverse la somnolence non seulement des personnages du roman mais celle éventuelle des lecteurs. Il est bien difficile de distinguer la frontière qui sépare le réel de l'irréel et le lecteur ressent comme une contamination de l'un par l'autre. "La vie parfois on dirait un rêve" déclare Madeleine ( $Z$. 144).

\section{RÊVE ET RÉALITEÉ}

Zazie dans le métro n'évolue pas explicitement de la vie "réelle" au rêve mais il est possible de supposer que le roman est le rêve de Zazie, ou le rêve de Gabriel, ou celui de Jeanne Lochère, ou leur enchainement, ou encore comme le déclame Gabriel au pied de la Tour Eiffel, "Le songe d'un songe, le rêve d'un rêve" (Z. 120).

Le rêve apparaît comme un intérêt présent dans l'oeuvre de Queneau. Il semblerait que cette préoccupation soit liée à l'analyse qu'il a suivie dans les années 30 et qu'il a évoquée plus ou moins discrètement dans son poème autobiographique, Chêne et Chien. 
S'agirait-il d'une clef permettant d'élucider des mystères ou d'un moyen litéraire pour parcourir la fiction, le rêve entretenant l'incertitude de toute signification? Dans Le Dimanche de la vie, Valentin Brû adopte intuitivement une curieuse attitude pour écouter les confidences de ses clients,

On l'avait d'abord trouvé bien causant, bien agréable, bien commercant. Lorsque, sur les injonctions de Julia, il s'était mis à questionner, discrètement bien sûr, les gens sur leur métier, leurs enfants et leurs malaises, puis sur leurs amours et leur situation financière, ... les intimités s'extravasaient d'elles-mêmes et des femmes qui venaient pour la première fois chez Valentin lui donnaient aussitôt la liste de leurs amants et l'état de leurs finances. Au café, même les habitués les plus coriaces lui racontaient leurs petites histoires dans le creux de l'oreille.... (D.V. 161)

Parlant du perroquet, un client de Turandot avoue que "ce genre de bestiau" lui donne des complexes; "- Faut voir un psittaco-analyste", lui répond Gridoux ( $Z$. 147). Zazie n'hésite pas à traiter Charles de "refoulé" et l'invite aussitôt à "raconter ses complexes" (Z. 89). Dans Les Fleurs bleues, Lalix refuse fermement d'écouter les rêves de Cidrolin: "Je trouve ça mal élevé, et pour ainsi dire malpropre" (F.B. 158). Cela peut être compris comme le refus d'aller découvrir "la fin fond des choses" (F.B. 157). Et pourtant Cidrolin trouve ses rêves particulièrement intéressants, "les miens, si je les écrivais, ça serait un vrai roman" réplique Lalix (F.B. 156) ... ou ce serait une autre lecture des Fleurs bleues.

Mais les rêves, en dehors de toute référence à la psychanalyse, sont également là pour interroger des définitions et des frontières, généralement admises, entre rêve et réalité et qui entretiennent en permanence l'incertitude de la signification. Chacun à son réveil 
éprouve une hésitation qui ébranle au moins pendant un temps au point de ne pas savoir toujours où il est et même qui il est et cela est d'autant plus troublant que les repères font défaut. D'où une inquiétude qui fait se demander à l'abbé les rêves qui le trompent: "Les uns viennent de Dieu et les autres du diable. Comment les distinguer?" (F.B. 41). Queneau suggère même d'aller plus loin. Lors de son voyage en Grèce, il avait emporté plusieurs livres, Le Discours de la Méthode, dont il sera question plus loin et aussi An Experiment with Time de Dunne, pour comprendre les rêves prémonitoires (V.G. 220). Un élément qui en annonce un autre légèrement modifié plus loin, comme il a été signalé auparavant, souligne l'omniprésence du rêve annonciateur dans Les Fleurs bleues, et pourrait suggérer qu'il s'agit aussi dans ce roman d'un mode de connaissance d'une autre réalité. La logique cartésienne, à laquelle il est souvent difficile d'échapper, fait s'éloigner du réel tandis que les rêves ou plus précisément "la connaissance inconsciente" (théorie des surréalistes) pourraient offrir un accès, mystérieux, certes, à un monde "vrai". Queneau, en jouant continuellement sur la confusion qui règne au moment du passage des frontières entre rêve et réalité fait accroître l'effet d'incertitude. Il plonge le lecteur dans un monde où vrai et faux sont indécidables, réalité et fiction indissolublement mêlées.

La traversée du temps (de l'histoire) par les rêves est reflétée dans l'agencement du texte en système d'échos. Plus généralement, la majorité de l'oeuvre de Queneau joue structurellement sur des système de rimes, de symétrie et sur la figure du double. Il n'est donc pas étonnant que des résonnances existent d'un roman à l'autre. 


\section{RÉPÉTITION ET JEU DU "JE"}

"Apprends épaisse de brute, que la répétition est l'une des plus odoriférantes fleurs de rhéthorique" réplique le duc d'Auge accusé de se répéter (F.B. 65). Narcense, dans Le Chiendent, avait prévenu les lecteurs, lorsqu'il répliquait à Pierre Le Grand: "... mais ne vous répétez-vous pas? Qui ne se répète pas? Il est moins habile que d'autres, voilà tout" (C. 34). Le principe de répétition est lié aux cycles et au mouvement circulaire et assure le maintient des mêmes choses en les répétant et en ramenant continuellement le retour. De plus, la répétition chez Queneau s'inscrit dans l'imitation des classiques dont il se réclame:

... cette originalité repose sur une connaissance de la tradition et des oeuvres anciennes; l'imitation en est toujours la source. Imiter, c'est le seul moyen de faire du nouveau... Victor Hugo est un classique parce qu'il a beaucoup imité; et parce qu'il a donc beaucoup innové. (V.G. 134)

La répétition s'inscrit aussi dans l'auto-citation. Bens cite deux formes de parodie dans l'oeuvre de Gueneau1: l'hétéro-parodie (référence aux oeuvres des autres) et l'auto-parodie qui renvoie aux propres ouvrages de l'auteur pour en faire un tout homogène. L'autocitation unifie l'oeuvre, créant un phénomène d'écho d'un roman à l'autre, dans un exemple d'intertextualité restreinte. Les personnages se répondent au-delà de l'histoire comme s'ils ne faisaient partie que d'une seule et même histoire. Ainsi, la servante Ernestine dans Le 
Chiendent, assistant à ses propres noces comme dans un rêve "sent croître dans son coeur une immense petite fleur bleue qu'elle arrose d'un pernod fils" (C. 261). Cidrolin évoque les campeurs qui s'éloignent de sa péniche: "Ils sont à peine partis que c'est tout juste si je me souviens d'eux" (F.B. 19) et reprend la méditation de Gabriel qui avoue ne savoir ceci qu'alexandrinement: "les voilà presque morts puisqu'ils sont des absents" (Z. 91). De la même manière, au cours de sa première visite à Paris, sa bonne "Ville Capitale", le duc d'Auge admire "la Sainte Chapelle, ce joyau de l'art gothique" (F.B. 23). Ce faisant, il reprend l'un des leitmotivs touristiques de Zazie dans le métro: "Where are we going now?" demandent les touristes. "A la Sainte Chapelle, répondit Fédor Balanovitch. Un joyau de l'art gothique" (Z. 93). Un peu plus loin dans le même texte, Gabriel répondra à ces mêmes touristes: "La Sainte Chapelle (silence) (geste) un joyau de l'art gothique (geste) (silence)." Et que dire de la compassion ironique de Zazie devant les effusions amoureuses de la veuve Mouaque: "Bonnes fleurs bleues dit Zazie qui alla voir le billard de plus près" (Z. 129). L'auto-citation peut jouer aussi à partir d'une citation déformée. Lorsque Le sire de Ciry décide d'émigrer, il lance au duc d'Auge: "Je quitte la France aux nouveaux parapets" (F.B. 214) et rappelle le narrateur de $\underline{\text { Zazie }}$ qui affirmait que le lendemain les voyageurs partaient "pour Gibraltar aux anciens parapets" (Z. 168) reprenant ainsi un vers du Bateau ivre d'Arthur Rimbaud: "Je regrette l'Europe aux anciens parapets" (Des bateaux ivres avaient dêjà été évoqués dans Le Chiendent 33). 
Les oeuvres de Queneau sont truffées de citations et de références classiques, là encore habilement dissimulées. S'il est plus ou moins facile de les identifier dans quelques romans, la tâche se revèle bien difficile dans d'autres, particulièrement dans Les Fleurs bleues, où le lecteur non averti se perd aussi du fait de leur abondance, mais Charles Baudelaire y est très présent par sa marque du voyage. A titre d'exemple, l'intertextualité générale est illustrée avec Victor Hugo, dont Queneau reprend, sous plusieurs variations, le vers suivant: "C'était l'heure tranquille où les lions vont boire", tiré de La Légende des Siècles. Dans Zazie dans le métro, "L'heure où les gardiens de musée vont boire" (Z. 99) fait écho à: "Car c'était l'heure où les houatures vont boire" des Fleurs bleues. L'auteur avait déjà amorcé ce vers dans son premier roman: "Les monuments continuaient à flotter sur ce liquide atroce où les jouets vont boire" (C. 122). Nombreux critiques ont évoqué et identifié les auteurs que Queneau a pastiché, parodié, ou paraphrasé. Jean Queval, en parlant de Queneau l'appelle "une caisse de rêsonnance de toute la littérature". Mais la transplantation de ces éléments existant ailleurs dans d'autres oeuvres littëraires est tantôt visible et repérable tantôt dissimulée ou détournée. Dans tous les cas elle n'est pas gratuite; elle concourt à masquer les problèmes de l'individu dans la société: "Ce nouveau masque, il l'arrache... et l'ayant froissé, le jeta dans les vatères" (C. 319).

Il y a des raisons de croire que des "signatures" personnelles de l'auteur sont cachées dans les textes. Si le jeu de l'apparence et de la réalité sous-tend tout Le Chiendent, le lecteur n'est pas dupe de la 
marque de l'auteur, au niveau psychanalytique. "Même un mégot cache sa vêrité" (C. 148), qui peut être lu comme un masque de 1'"ego", d'autant que cette hypothèse est renforcée par la récurrence du mot le long du texte. De la même façon, si le roman est comme "un jeu de cache-cache" (C. 148), le lecteur ne peut plus s'étonner de voir dissimuler dans la lettre de Saturnin à l'adresse d'Etienne et de Pierre Le Grand les "Vous voilà quinauds", ou encore l'insistance à appeler les chaussures, "les croquenots". C'est probablement un moyen d'attirer l'attention sur la fiction de tout texte et d'insister sur son aspect artificiel. Même si l'auteur déguise son moi à l'occasion (duc d'Auge = $Q$ d'ego par une lecture en sens inverse), d'autres fois il rappelle nettement sa présence; témoin ce passage où Gabriel au pied de la Tour Eiffel déclare: "et toute cette histoire... à peine plus qu'un délire tapé à la machine par un romancier idiot (oh! pardon)" (Z. 90). Encore dans Le Chiendent la façon ironique à l'égard du roman considéré sous l'aspect le plus concret et matériel est soulignée lorsque Saturnin prévient le lecteur que ce sera bientôt fini et le renvoie au numéro de la page en haut et à droite. Des interventions de cette sorte sont une caractéristique fréquente du roman cité. Par exemple, le narrateur fait semblant d'être concerné par la précision de ses énumérations en se demandant "voyons-voir si je n'oublie rien" (C. 22) ou encore, lors d'une description de la banlieue, il souligne soudain sa propre fantaisie: " à 'Mon-Repos', un canard hurle parce qu'il vient de se casser la patte en faisant du trapèze volant (c'est pas vrai)" (C. 176). La marque de Queneau est encore plus nette à la fin de 
l'ouvrage, au cours d'une conversation entre Etienne, Saturnin et Mme Cloche:

- C'est pas moi qui ai trouvé ça, dit la reine. C'est dans le livre.

- Quel livre? demandèrent les deux maréchaux errants.

- Eh bien, çui-ci. Çui-ci où qu'on est maintenant, qui répète c'qu'on dit à mesure qu'on l'dit et qui nous suit et qui nous raconte, un vrai buvard qu'on a collé sur not'vie.

- C'est encore une drôle d'histoire, ça, dit Saturnin. On se crée avec le temps et le bouquin vous happe aussitôt avec ses petites paches de moutte. (C. 429)

La contrepèterie "pattes de mouche" met en évidence l'intrusion de l'auteur et accentue la réflexivité des romans; d'une part il annule symboliquement l'intrigue centrale (la porte du père Taupe est réduite en morceaux, objet qui fut la convoitise de tous les personnages) et d'autre part, il arrive même à "littératurer" (littérature+raturer) les personnages qu'il a crées et ainsi les fait disparaitre comme le signale

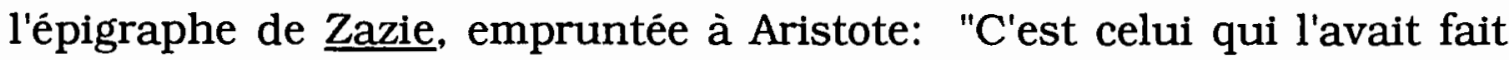
qui l'a fait disparaitre."

Rimes de situations, de lieux et de personnages concourent à donner aux romans de Queneau leur unité, et leur fermeture sur euxmêmes souligne leur conception classique. Simonnet avec Le Chiendent en particulier et l'analyse que fait Barthes de $\underline{\text { Zazie tendent }}$ à prouver que les unités de temps, de lieu et d'action sont respectées. Gerald Prince, par contre pense que l'oeuvre romanesque de Gueneau est placée sous le signe de l'anti-roman, à l'exception d'Odile et d' $\underline{\text { Un }}$ rude hiver, soulignant le fait que pour décrire un monde où chaque élément se donne pour ce qu'il n'est pas, le romancier adopte une forme romanesque constituant elle-même une attrape en se révélant graduellement comme étant le contraire de ce qu'elle semblait être. 
De ce point de vue, les romans de Gueneau se rapprocheraient de plus en plus du texte-objet dont "rêvait Flaubert et que, de nos jours, un Robbe-Grillet ou un Butor s'évertuent à construire" (Prince 39). Alain Robbe Grillet faisait remarquer dans son livre Pour un nouveau roman:

Je ne transcris pas, je construis. C'était déjà la vieille ambition de Flaubert... Il faut souligner ici l'importance des romans de Queneau (Le Chiendent en particulier) dont la trame souvent et toujours le mouvement sont d'une façon rigoureuse ceux de l'imagination. (Robbe-Grillet 177).

Là encore c'est à chacun à trouver sa propre clef de lecture. Queneau considérant que toute technique de roman est arbitraire, il adopte les conventions existantes et les remet en question, procédé qui fait prendre conscience que dans le monde qui nous entoure le paraître ne correspond peut être pas à l'être. L'anonymat troublant des personnages et leur comportement imprévisible, contradictoire, inexplicable sont déconcertants à travers leurs envolées métaphysiques dont la portée dissimulent des questions fondamentales. 


\section{CHAPITRE IV}

\section{L'ÊTRE ET LE PARAÎTRE}

La vêritê! s'écrie Gabriel (geste)... Comme si quelqu'un au monde savait cexé.

- Raymond Queneau, Zazie dans le métro

\section{APPARENCE ET RÉALITE}

La vérité et le mensonge, les mystères d'évènements jamais élucidés, les déguisements et les transformations permanentes, les silhouettes et leurs attributs et plus généralement la réalité derrière les apparences, est une constante caractéristique de toute l'oeuvre de Queneau et qui fait prendre conscience à travers ses personnages de questions particulièrement importantes sur les conditions d'existence.

Un premier exemple est donné par les journaux qui jouent une importante part dans la vie de la majorité des personnages de Queneau: "Les journaux, ils romancent, je les connais" dira Pierrot (P. 158). Le lecteur se souvient des affabulations de Zazie qui, avec son assurance, déconcerte totalement ses différents interlocuteurs. Mensonges et trucages sont aussi délibérés que les deux centimètres en moins du mètre de Julia dans Le Dimanche de la vie. Valentin Brû ment consciemment à Houssette et admire "la facilité avec laquelle il avait crée dans l'esprit raisonnable de l'épicier une petite zone d'erreur" (D.V. 205) ou une zone de trouble propice à l'illusion. Cette 
dualité du langage dont Zazie use quand elle "se tient de grands discours avec sa petite voix intérieure" $(Z$. 56) repose sur une découverte essentielle de Valentin qui "pensait que le langage devait formuler la vérité et le silence la cacher" (D.V. 206). Entre dire la vérité et taire l'erreur, il y a donc une voix possible qui est celle du trouble et en conséquence celle du doute: "On admet la sincérité de toute apparence, alors qu'au contraire il faut en douter" (C. 326).

En ouvrant un livre de Queneau, l'atmosphère est communiquée immédiatement par le flou, l'incompréhensible et une "inquiétante étrangetē". L'ouverture de Zazie se fait sur un mot dont l'écriture est complètement étrangère à toute expérience vécue. Qui est Gabriel? Un veilleur de nuit qui a du rouge aux lèvres et qui se parfume avec Barbouze de chez Fior ou un artiste qui danse la mort du cygne dans un cabaret d'homosexuels, qui ne boit que des grenadines bien tassées et qui écrase de temps à autre une larme au coin de l'oeil? Marcelline est présentée comme sa femme mais elle est révélée être Marcel, seulement à la dernière page et pourtant par une relecture plus attentive la mère de Zazie l'a habilement signalé, d'autres personnages le savaient-ils aussi? De tels changements d'identité sont largement présents également dans Pierrot mon ami; Jojo Mouilleminche alias Chaliaqueue ou Toricelli convainc Mounnezergues qu'il est un prince royal au nom de Voudzoï, puis se fait passer pour Voussois, un marchand d'animaux de cirque tandis que son frère Robert prend le nom de Crouïa-Bey, fakir à l'Uni-Park. Pierrot lui-même malgré "l'épaisseur des lentilles de ses lunettes", confond Mounnezergues avec son mannequin de cire et quand on lui demande de les enlever 
pour mieux voir, il ne distingue plus rien et plus personne dans le brouillard. Le beau-frère du héros du Dimanche de la vie change de nom toutes les fois qu'on parle de lui. La difficulté à identifier les personnages est bien due au fait qu'ils apparaissent sous des masques différents. Le "type" qui se fait appeler Pedro-surplus, vendeur de blue-jeans au marché aux puces est un satyre, selon Zazie, mais il se révélera être sergent de ville, au nom de Trouscaillon;

C'était pas un satyre qui se donnait l'apparence d'un faux flic, mais un vrai flic qui se donnait l'apparence d'un faux satyre qui se donne l'apparence d'un vrai flic. (Z. 59)

Satyre ou flic? A mesure que le récit progresse, il est de plus en plus difficile de le dire. Lui-même doute "de la vertu de l'uniforme et de son sifflet" (Z. 145); quand il essaye de se joindre au groupe des civils qui veut porter secours à Gabriel, deux vrais "hanvelos" le prennent pour un prêtre déguisé. Plus tard, Gabriel ne pourra le reconnaître dans son costume de civil endimmanché, à côté d'une rombière, la veuve Mouaque "comme tout le monde". Il avoue à Marcelline, que les déguisements l'amusent au moment où il se présente à elle en tant que l'inspecteur Bertin Poirée, ignorant luimême qu'elle est un homme. Avec ou sans bacchantes, "c'est comme vott tutu, juste un déguisement pour s'amuser", dira-t-il plus tard à Gabriel(la). En effet, à la fin du roman, Pedro-surplus se transforme en une autre figure, en despote, au nom d'Aroun Arachide. Par contre, à Fédor qui lui reproche de ne guère varier son "truc", Gabriel réplique: "Qu'est-ce que tu veux, les artisses, c'est comme ça" ( $Z$. 123). Et pourtant, le lecteur continue à voir défiler encore d'autres déguisements dans Le Chiendent, ce qui fait dire à Simonnet que les 
"personnages ne sont pas ce qu'ils sont et sont ce qu'ils ne sont pas" (Simonnet 67). Mme Cloche est habillée en curé pour tenter de s'approprier le trésor du père Taupe tandis que Saturnin porte une fausse barbe. La véritable identité de Peter Tom demeure incertaine bien que ses pouvoirs soient indiscutables. En attendant les invités de la noce d'Ernestine:

Peter Tom l'Anachorète prend un Paris-Midi qui traîne sur table, en fait un cornet, place l'animal dedans, pose le tout sur le zinc, sort un pistolet de sa poche, tire sur le journal, le déplie: le cobaye a disparu et Paris-Midi est devenu Paris-Soir quatrième sportive. Les applaudissements crépitent, le magicien salue et la noce n'est pas encore là. (C. 253)

La confusion des identités, de personnes comme de lieux, les masques et les démasquages, la présence de fakirs ou de prestigitateurs, tous ces éléments troublent le lecteur d'autant que parfois il lui faut attendre bien longtemps avant même d'identifier les silhouettes.

Au commencement du Chiendent les personnages ne sont nommés que par des termes vagues: l'autre, le type, la femme, la silhouette. Au fur et à mesure que les caractères principaux se dessinent les personnages secondaires et marginaux restent imprécis: "Un personnage indécis comme le reflet d'un réverbère dans une flaque de boue" (C. 386). Les passagers des trains de banlieue sont des journaux qui se déplient et se replient ou des formes dégonflées par le sommeil. L'apparence tant des êtres que des choses est comme un tic tout au long du roman et le lecteur s'interroge sur la substance ou la véritable identité de tout ce monde qui s'agite. Etienne qui se 
félicitait de ses immenses progrès dans le maniement des concepts déclare:

Tout ce qui se présente se déguise. Ainsi, par exemple, la chaussure droite du type qui se trouve en face de moi. Bien sûr elle parait chausser son pied: elle parait... Toute chose a de multiple apparences, une infinité d'apparences... Et les hommes, c'est encore pis que les choses. (C. 328)

Il souligne de ce fait le caractère illusoire du monde environnant et la difficulté de voir derrière les apparences. Queneau a déja mis son lecteur sur la voie par les termes qu'il fait tenir à un autre personnage: "Je suis, je, Prince de ce monde... il me plait de parcourir mon domaine sous des aspects variés en prenant les apparences de l'incertitude et de l'erreur" (Z. 185). Le lecteur n'est pas dupe pour autant de l'intrusion de l'auteur. Le "je" est le créateur d'illusion par métamorphoses. En soulignant, dans un entretien avec Marguerite Duras, que le personnage essentiel du livre (Zazie dans le métro), c'était plutôt Trouscaillon, il se démasquait lui-même et montrait son visage aux multiples facettes'.

Parlant de son premier roman, Le Chiendent, Queneau affirme (V.G. 219) que lors de son voyage en Grèce, il avait en tête de traduire Le Discours de la Méthode en néo-français, livre qui faisait partie de ses bagages mais le projet n'a jamais vu réellement le jour. En un sens cependant, René Descartes lui avait donné l'exemple puisqu'il avait écrit son ouvrage en français et non en latin et par là même, il avait démontré que tout langage peut-être un véhicule pour exprimer ses idées. En tout cas, compte tenu de l'extrême variété des dialogues, Le 
Chiendent pourrait être assimilé à une ambition cartésienne: rendre le langage ordinaire capable d'exprimer la réalité ultime, même si, dans le cas de Queneau, cette réalité est finalement dissoute dans le jeu des apparences.

Le problème central de l'approche cartésienne est de distinguer la vérité des apparences décevantes. Queneau force le lecteur à confronter cette difficulté de l'extérieur en l'obligeant à analyser les apparences qui sont observées par un personnage un peu exceptionnel, à moitié en dehors du récit et hors de la banalité. Cet observateur, Pierre Le Grand, commence le roman en regardant la plus banale des scènes parisiennes à savoir la foule des banlieusards aux heures de pointe qui essaient d'attrapper leur train pour rentrer chez eux. Puis il fixe son attention sur une silhouette, qui se révélera être un simple employé de banque du nom d'Etienne Marcel. Plongé dans l'anonymat de la vie quotidienne, il n'en émergera que peu à peu au prix d'une laborieuse interrogation cartésienne; alors, il deviendra, plus tard et à son tour, un observateur des apparences.

La transposition et l'éclairage du réel s'effectue donc à travers le banal et l'insolite. Dès les premières pages du récit, malgré le ton solennel, l'être s'oppose au paraître à plusieurs reprises, un des thèmes majeurs du roman dans sa totalité. Le lecteur est introduit immédiatement dans une sorte de "traversée des apparences" comme dans Zazie (Simonnet 63). Si la méditation prend des formes diverses, à l'origine, il y a une découverte primordiale, celle de la banalité du réel. Après un orage à Paris en été, Pierre le Grand écoute s'échanger des considérations météorologiques et "il constate avec 
amertume que ces banalités correspondent parfaitement à la réalité. La réalité présente n'en demanderait-elle pas plus" (C. 22). Mais cette apparition du banal, en la regardant mieux ou un peu de biais, comme Etienne, a quelque chose d'insolite. La prise de conscience de la banalité de l'existence chez Etienne est en corrélation avec sa prise de conscience de son caractère saugrenu et déroutant. Les petits canards, le chapeau "ouatteurprouf", la baraque à frites et l'épluchepatates sont autant d'apparences insolites situées en dehors de la routine quotidienne.

En plus, les observations de Pierre Le Grand modifient ce qui est observé; en suivant du regard Etienne, son action même d'observer transforme le personnage à une dimension en un être à trois dimensions. Mais quand Pierre disparait temporairement de l'horizon d'Etienne, ce dernier aussitôt s'ennuie, se dissout, s'efface et s'annule. Lorsque Pierre disparaît définitivement, Etienne Marcel "lentement, doucement se sent diminuer" (C. 386) ${ }^{1}$. Mais dans le domaine de la relativité, le point fixe de l'observateur cartésien, s'il n'est pas une illusion n'est rien d'autre qu'un point arbitrairement choisi. On pourrait multiplier indéfiniment le nombre de points d'observation pour voir "le réel" et Queneau offre ainsi au lecteur un "je" qui observe Pierre aussi bien que d'autres personnages qui interviennent directement pour dire ce qu'ils voient. Cependant personne ne peut percer le mystère au coeur du livre et qui est l'apparence de Pierre:

1 Il est intéressant de noter qu'un contemporain de Queneau, Gabriel Marcel, philosophe-méthaphysicien a orienté ses recherches, dans les années 1950 , vers Le Mystère de l'Etre ; il étalt convaincu que le moi n'avait d'existence et de valeur que dans sa coexistence avec un soi . 
est-ce un personnage, un magicien qui manipule le monde ou peutêtre un gangster avec un frère "Cantorien" comme le croit Mme Cloche. C'est en quelque sorte une mise en abyme de l'oeil littéraire qui suit des observateurs observant des observateurs, un ensemble de personnages perdus dans les apparences des évènements, des situations et des autres personnages eux-mêmes.

Observant Etienne, Pierre le suit jusqu'à sa maison de banlieue où cet anonyme vit avec son fils et sa femme. Elle, à son tour est observée et suivie par Narcense et Potice qui sera "laminé" par un autobus, scène à son tour observée par Mme Cloche dont le frère Dominique est propriétaire d'un bistrot où Pierre et Etienne feront connaissance. Narcense, lui-aussi, est observé par le concierge de son immeuble, écrivain en herbe et frère aussi de Mme Cloche. Tous observent le père Taupe derrière la porte duquel un trésor est supposé être caché. Ne se fiant qu'aux apparences, Mme Cloche décide que Pierre et Etienne sont des gangsters qui veulent s'approprier le soi-disant trésor et décide d"arranger" un mariage entre le père Taupe et la servante Ernestine. Des décennies plus tard, après des situations et des évènements aussi absurdes que les personnages, ces derniers, fatigués de la façon dont le roman les observe, décide de "littératurer" le livre et de retourner au début tandis qu'"un masque traversa l'air, escamotant des personnages aux vies multiples et complexes, et prit forme humaine à la terrasse d'un café" (C. 432). Le temps est effacé, et l'ouverture du roman réapparait (ainsi qu'il l'avait été signalé lors de l'analyse structurelle). Le cercle complet est bien la seule figure géométrique qui peut décrire la nature 
de ce qui est. Les apparitions sont soulignées comme les disparitions: "... on ne les reverra plus... ils s'éloignent et pour ainsi dire meurent" (C. 311 ) et qui fait écho à la remarque de Gabriel dans Zazie, "les voilà presque morts puisqu'ils sont des absents" ( $Z$. 91). La multiplicité des modes de narration, lettres, télégrammes, journaux et articles, dialogues et conversations, monologues intérieurs et courant de conscience, discours indirect et même les réflexions du chien Jupiter, sont autant de points de vue dont la prolifération démontre la difficulté de pouvoir saisir ce qu'on pourrait être tenté d'appeler la vérité. Blaise Pascal estimait qu'aucun discours était pleinement rationnel pour définir "la" vérité de son objet, puisque le nombre de "ses" vérités, toutes particulières, dépasse la capacité de synthèse de l'esprit humain.

\section{EXISTENCE ET NON-EXISTENCE}

Dans la célèbre allégorie de La Caverne de Platon, les prisonniers plongés dans l'obscurité, prennent pour des réalités en soi les ombres des objets qui sont manipulés dans leur dos, à la lumière d'un grand feu. Ce dont ils souffrent, c'est du trop plein d'apparences immédiates, auxquelles ils adhèrent fanatiquement et il leur faudra procéder par étapes pour pouvoir être confrontés aux réalités, sinon ils seraient aveuglés par l'excès de lumière. Il ne faut donc pas se laisser séduire par la multiplicité des apparences toujours différentes de l'être. Aussi Etienne devra passer par des étapes successives et notamment de doute avant de se découvrir lui-même et d'accéder à une certaine connaissance de la réalité. 
Les interrogations de Platon et Descartes sont bien en toile de fond permanente dans Le Chiendent: qu'y-a-t-il derrière les apparences? Thêo, le fils d'Etienne, lit une Apologie de Socrate, mais il médite moins sur les idées de Platon que sur l'image obscène qu'il a cachée dans le volume. Les apparences sont bien décevantes. L'apparition ne coïncide pas rigoureusement avec le réel; elle le révèle, mais aussi elle le masque. L'attitude d'Etienne le conduit à douter de tout ce qu'il voit;

Il croyait savoir et il ne savait pas. Il croyait connaitre et il ne connaissait pas. Le monde, comme un jeu de cachecache, de nouveau, il eut cette vision. On admet la sincérité de toute apparence, alors qu'au contraire il faut en douter... Etienne douta du monde. Le monde se jouait de lui. (C. 218)

Comme Descartes, Etienne, à la recherche du savoir, a ses moments de doute. Face à l'énigmatique porte, il se demande si tout ce qu'il perçoit a une existence. Et en même temps, il doute des apparences quand il pense que Mme Cloche le prend pour un gangster. Avec ce paradoxe, le raisonnement cartésien semble aboutir à l'impossibilité de décider ce que l'apparence est. Il n'est pas étonnant qu'à la fin, rencontrant Mme Cloche, il décide d'effacer le tout.

En même temps, en dépit de sa méfiance envers les apparences, Etienne est fasciné par elles. Il demeure convaincu qu'il doit exister quelque vérité, quelque signification derrière elles;

Il $\mathrm{y}$ avait un secret derrière ce port de pêche, il y avait un mystère derrière cette falaise, derrière cette borne, derrière ce mégot. (C. 218) 
Aussi, il se persuade qu'il y a quelque chose derrière la porte bleue du père Taupe, objet de la fameuse chasse au trésor. Mais cette croyance se révélera complètement infondée; la porte ne dissimule absolument rien de valeur si ce n'est un reste de souvenir attaché à une histoire sentimentale que Taupe aurait eue étant jeune. Pierre Le Grand, quant à lui, représente l'ultime stage du doute. A la différence d'Etienne, Il hésite d'abord à croire que la porte du père Taupe renferme quelque vérité ou signification: "Je doute qu'elle ait quelque valeur" (C. 120), et il se prépare à l'accepter, contrairement à Etienne:

- Pour moi, aussi, dit Pierre, les choses, le monde n'a pas la signification qu'il se donne, il n'est pas ce qu'il prétend être...

- C'est comme ça que vous pensez? interrogea Etienne. Moi je disais: on croit voir une chose et on en voit une autre.

- Et moi je dis, on croit voir une chose, mais on ne voit rien. (C. 187)

Queneau utilise différents courants de pensée philosophique et les traite de multiples façons pour servir à ses fins. Il signale effectivement dans Pierrot mon ami que" les philosophes sont des voyeurs" (P. 88). Etienne graduellement atteint l'"être pour soi", quand il passe de l'être inconscient à un être à trois dimensions et en même temps l'"être pour autrui", quand il devient un objet d'observation pour l'autre individu, Pierre Le Grand qui le suit. Ceci survient quand il brise ses habitudes et commence à penser. Queneau a pu avoir l'intention à l'origine de s'inspirer du fameus cogito "Je pense donc je suis" de Descartes qui, à la recherche de l'être, a consacré ses méditations sur le doute. Le philosophe s'était acharné à nier ses croyances et tout ce qui l'entourait: "Toutes les choses que je 
vois sont fausses... rien n'a jamais été de tout ce que ma mémoire remplie de mensonges me représente" (Méditation II). Mais il y avait une chose dont il était sûr, c'est qu'il devait exister puisqu'il doutait. Je doute donc j'existe en tant qu'être pensant. Cela signifie bien que la pensée était la preuve de l'existence et non la cause: douter c'est penser, penser c'est exister. Le héros de Queneau, par contre, vit une expérience différente qui peut être présentée de la façon suivante: Je pense et je découvre que je suis. Je pense un peu plus et je ne sais plus qui je suis. Je pense encore plus et je ne sais plus si je suis. Queneau décrit ainsi trois phases d'un nouveau type d'existentialisme, celle de l'incertitude, celle du doute et celle du scepticisme. Etienne accepte à la fin que les apparences peuvent être décevantes: "On croit faire ceci et puis on fait cela. Toute action est déception, toute pensée implique erreur" (C. 187), alors il est réabsorbé dans la banalité précédente et il redevient un être plat. Accusé de scepticisme, il offre une réponse claire: "Ce n'est pas être sceptique de détruire l'erreur, et quelle erreur plus grave que de croire savoir ce qu'on ne sait pas". (C. 163). L'erreur est humaine.

Queneau s'amuse aussi à parodier Platon par l'intermédiaire d'autres personnages. Ernestine, brusquement se sentant mourir pendant son repas de noces, aimablement invite la foule à entrer dans sa chambre et "prit la position de Socrate buvant la cigüe" (C. 299). Narcense déclare que l'essence des choses est de n'avoir aucune essence après avoir clairement prévenu qu'il était dénué de scepticisme et de plus qu'il n'était pas philosophe. Il voudrait que les objets qui l'entourent "fussent éternels comme cette lampe Mazda 
poussiéreuse et ce chien qui rêve sur le marbre. Et leur qualité essentielle, c'est précisément de ne pas l'être" (C. 35).

Les méditations cartésiennes d'Etienne sur l'apparence se doublent de celles du concierge Saturnin qui, lui aussi, doutant de tout et d'une manière consistante analyse les différents modes de l'être et du non-être. Il présente d'abord son point de vue sur la philosophie; selon lui, elle aurait fait deux grandes fautes: non seulement d'avoir oublié d'étudier les différents mode d'être, mais, ce qui est le plus important, ceux de ne pas être:

Ainsi une motte de beurre, j'prends l'premier truc qui m'passe par l'idée, une motte de beurre par exemple, ça n'est ni un caravansérail, ni une fourchette, ni une falaise, ni un édredon. Et r'marquez que c'mode de ne pas être, c'est précisément son mode d'être. J'y r'viendrai. Y en a encore un autre mode de ne pas être: par exemple, la motte de beurre qu'est sur cette table, n'est pas. C'est un degré plus fort. (C. 375)

Le lecteur reconnait là un raisonnement autour des thèses de Parménide qui a été le premier à formuler le problème de l'être: "L'étant est être, et le néant n'est pas". Queneau avec une dextérite assez étourdissante, jongle avec les grands mots philosophiques, être et non être et les transpose dans des termes plaisamment familiers. La démonstration qui s'étale sur plusieurs pages est des plus déroutantes et se termine par les conclusions suivantes:

... j'vous répète encore un coup pour que vous vous les mettiez bien dans le crâne

L'être est, le nonnête n'est pas,

L'être n'est pas, le nonnête est,

L'être est, le nonnête est,

L'être n'est pas, le nonnête n'est pas, 
et aboutit à ce constat ironique: "C'qui fait que la vérité est encore ailleurs" (C. 377). Le discours philosophique démontre son impuissance à envisager la totalité, obligé de reconnaître qu'il ne saurait énoncer toute la vérité. L'incertitude est plus que simple ignorance, elle masque tout le réel. Gabriel, dans ses âpres discussions avec Charles l'avait déjà clairement énoncé au début du roman: "La vérité!... comme si tu savais cexé. Comme si quelqu'un au monde savait cexé... tout ça, c'est du bidon... Oui, du bidon" (Z. 17).

Il convient donc de ne pas trop s'hypnotiser sur la trompeuse notion de spectacle. Pierrot, d'ailleurs, essuie systématiquement ses "bésicles", après avoir regardé autour de lui. Mme Cloche n'a pas cette prudence. "Elle ne se limite pazozap-parences", mais elle se trompe. Elle a pris Etienne pour un gangster, le Père Taupe pour un millionnaire, un sinistre remblai pour un trésor, autant d'illusions qui illustent l'insensé et l'absurde.

\section{L'ANGOISSE}

Avant même son jeu de l'être et du néant, Saturnin avait déjà abordé le problème pendant la noce du Père Taupe et de la servante Ernestine: "Alors ils sont désespérés. Ils ne se doutaient pas que l'assiette pleine cachait une assiette vide, comme l'être cache le néant" (C. 267). Si seulement le temps pouvait s'écouler, sans heurt et sans fin mais "Les assiettes ont un fond et, dans ce fond, le potachistagneu" (le potage y stagne) (C. 268). Cette parodie de l'existence humaine fait écho au soliloque de Gabriel dans Zazie: "L'être ou le néant, voilà le problème" (Z. 90), et son deuxième 
discours à la terrasse du Café des deux Palais renforce le thème sur le problème de l'existence, par sa remarque sur la précarité de la vie: "... il suffit d'un rien pour vous en priver. Un rien l'amème, un rien l'anime, un rien la mine, un rien l'emmène" (Z. 117). Même Trouscaillon réfléchit sur la fragilité des choses humaines en observant un groupe de clochards à l'entrée du métro. Saturnin a aussi ses moments d'angoisse quand, essayant d'écrire dans son petit livre, il découvre qu'il a peu de pouvoirs sur les idées qui lui passent par la tête et plus encore quand il croyait avoir des choses à dire et qu'en fait "Y a rien" (C. 180), même si plus tard il découvre qu'il peut écrire sur ce qui n'existe pas.

Selon Pierrot, ce n'est pas que rien ne soit, c'est plutôt que rien n'est durable:

Tout change vite sur cette terre. Rien ne dure... Si on dit qu'il fait jour, quelques heures après, il fait nuit et si on dit qu'il fait nuit, quelques heures après il fait jour. (P. 139)

L'existence humaine ne s'écoule pas toujours d'une facon aussi paisible ainsi que semble le ressentir Pierrot. Des situations angoissantes peuvent s'y dresser comme l'explique Ernestine aux gens de la noce:

En résumé, que j'dis, j'disparais comme y en a tant d'aut's qu'ont fait avant moi et comme y en aura encore plus qui l'front après. Voilà. (C. 303)

Mais Ernestine naïvement trouve étonnant que cela lui arrive à elle:

... j'vous dirai donc que ça m'épate un peu de disparaître... et quand n'importe quoi disparaît c'est déjà drôle. Mais moi. Ça alors, ça d'vient renversant. (C. 300-301) 
Et elle se pose alors la question du sens de son existence: "V'la que je meurs, qu'est-ce que j'aurai foutu ici?" (C. 301). Ernestine sait qu'elle va mourir et que les autres de la noce "attendent comme qui dirait un train", mais ils ne veulent pas et ne peuvent pas la comprendre, ils ne font que l'écouter parler, elle est donc obligée de se placer à leur niveau, dans la banalité, ou se taire: "J'voudrais bien donner des précisions, mais vous comprenez j'peux pas" (C. 302). Son ultime angoisse surgit quand elle réalise l'existence de sa propre mort. Elle ne trouve plus les mots, le silence alors s'établit. Elle a pris conscience du temps qui s'écoule et qui se rompt brutalement comme le fil de la vie que deux des Parques filaient, dévidaient et que la troisième, Atropos, coupait. Ernestine n'est pas la seule à se voir mourir, un personnage au moins, dans chacun des romans étudiés, disparait brutalement et la mort est un thème très présent dans la plupart de l'oeuvre de Queneau. L'auteur lui a même consacré tout un recueil de poèmes, L'Instant fatal, dans lequel, à l'évidence, il éprouve horreur et terreur, et s'il la ridiculise, c'est probablement pour réduire sa crainte à son égard. Aussi Queneau oscille constamment entre deux extrêmes, d'un côté l'angoisse, la mort, le vide de la vie et de l'autre, la plénitude de la vie, la frénésie de vivre, autant de thèmes qu'il mêle les uns aux autres et avec lesquels il joue.

Deux solutions sont possibles pour répondre au doute existentiel: la sagesse populaire mais aussi l'anonymat qui est une forme de réponse dans le temporel. 
La tyrannie du temps est un des grands thèmes dans l'oeuvre de Queneau. Les personnages sont esclaves de cette pression quotidienne et cyclique sans même qu'ils s'en aperçoivent. Ils s'agitent de façon absurde au sein d'une vie quotidienne qui se répète sans fin, anonyme et inauthentique. Les cheminements bordelais et parisiens de Valentin Brû sont aussi confus que les itinéraires de Pierrot qui, lui, n'a aucun contrôle sur sa vie. Il passe son temps à déambuler ou à tourner en rond, seul. Comme Meursault, L'étranger de Camus, il est en marge de la société, de "la grosse bête Société" (P. 153);

De temps en temps, Pierrot ferme les yeux, et il saute comme ça dix minutes, un quart d'heure. Quand il rouvre les yeux, tout est pareil. Alors il recommence à attendre, il reprend une cigarette, et de nouveau de lents et rares pouf-pouf de fumée se traînent à mi plafond. Il y a un gros soleil couché devant la porte, ouverte sur le balcon. De grosses mouches entrent faire un tour, puis ressortent irritées. Des petites se baladent un peu partout. (P. 48)

Valentin passe beaucoup de temps à regarder les aiguilles d'une horloge publique pour mettre sa montre à l'heure, sans qu'il y parvienne d'ailleurs, plutôt pour se vider "les tuyaux de la tête", ou bien il bavarde de tout et de rien avec ses voisins; s'il médite sur la bataille de Jena, il n'y pense pas vraiment tout comme Pierrot qui fait semblant de réfléchir à la mort de Louis XIV mais

... n'avait dans son esprit qu'une buée mentale, légère et presque lumineuse comme le brouillard d'un beau matin d'hiver, qu'un vol de moucherons anonymes. (P. 19)

En règle générale, les personnages de Queneau ne sont pas de grands penseurs, ce qui les éloignent du héros de Camus ou de Roquentin de Sartre qui, lui, déniait les possibilités du passé. Quand 
ils pensent, c'est plutôt exceptionnel. L'ami Pierrot reconnaît qu'il lui arrive "souvent de penser à rien. C'est déjà mieux que de ne pas penser du tout" lui fait observer le veilleur de nuit (P. 166). Les autres se perdent souvent dans le labyrinthe de leurs réflexions.

Beaucoup de personnages, indifférenciés, sont jetés dans la multitude et dans la foule, telles des "mouches noirâtres, ou accrochés aux portes cochères, comme des moules aux pilotis d'une jetéepromenade" en attendant que la pluie cesse (C. 21). Les quais tout noirs sont comparés à du papier à mouches. La foule est vue aussi par Queneau comme un grouillement d'individus. Les "poissons cavernicoles" de Saint-Glinglin lui suggèrent de parlantes méditations:

C'est vraiment atroce la vie de poisson de banc... On nait en choeur par millions, puis tous ensemble, nous allons, nous harengs fraternels, traverser les mers démesurées, nous serrant les nageoires.... C'est cela notre vie à nous harengs. Et celui qui se trouve au milieu du banc? Des millions de congénères l'entourent. (G.G. 20)

La banlieue, zone géographique indécise reprêsente le sinistre développement de la ville. Le trimbalage collectif ne fait que prolonger et amplifier l'anonymat des foules urbaines. Les possesseurs de journaux se précipitent avec courage dans des effroyables mêlées et quand ils sont casés, "on clôt le récipient" (C. 37), puis ils sont "empochés" et immédiatement "avalés par l'ombre" (C. 9), et après, ils se retrouvent assis en face ou à côté de visages silencieux et inexpressifs, à ne rien faire attendant que le temps passe, à moins que leur regard baissé ne se pose sur les chaussures de leurs voisins qu'ils détaillent avec beaucoup de minutie. Une fois l'aller-retour et la 
journée de travail terminés, une visite au café du coin s'impose et boucle la boucle;

Le sergent Bourrelier poussa la porte du café des Amis et il entra, suivi du soldat Brû. Ils s'installèrent à leur place habituelle et, sans qu'ils lui eussent rien demandé, Didine leur apporta le tapis vert, les cartes grises, un pernod pour Arthur et le vin blanc gommé du soldat Brû. (D.V. 34)

Queneau prolonge cet environnement fait d'habitudes par la répétition des activités sociales, autre série de routines auxquelles les personnages ne peuvent échapper, et qui complètent leur existence, leur aliénation à la vie de tous les jours. Il s'agit non seulement de rendre sa tournée au risque de s'enivrer, il faut que Valentin, comme les usages le veulent, témoigne sa reconnaissance à Bourrelier, l'homme qui lui apporte "un riche mariage tout cuit et pour ainsi dire sur un plat" (D.V. 38). D'autres rites, plus sombres, sont décrits systématiquement, notamment à l'occasion de funérailles. Ces scènes traitées à la façon la plus humoristique sont en même temps très émouvantes pour le lecteur français, par les détails d'un réalisme déconcertant. A d'autres occasions plus plaisantes, les conventions l'emportent également sur le choix individuel, par exemple quand il s'agit des sorties en famille le dimanche pour prendre l'air;

Le Bois, naturellement est envahi. Des gens ont picniqué et le papier gras s'étale. On dort çà et là... Etienne à son bras sent sa femme se pendre. Lui, conduit sa famille suivant l'habituel itinéraire. On ira jusqu'au vieux château; là, repos; puis on descendra jusqu'à la rivière, à la petite guinguette; limonade, et puis retour...

Mais il est temps de rentrer. La foule commence à se diriger vers la gare. $6 \mathrm{~h} 1 / 2$. On attendra une demiheure le dîner, puis la pipe, un dernier tour au jardin, la nuit, le sommeil. Demain, le travail recommence. (C. 56) 
Les conventions sociales imposent donc aussi des habitudes mécaniques, même les jours de repos, que personne n'essaye de rompre et qui accentue le rythme plat et monotone du train-train de la semaine. Des évènements atroces peuvent surgir mais ils ne bousculent pas pour autant les habitudes, surtout celles de Mme Cloche qui ayant assisté à la mort de Potice, "laminé" par un autobus, vers la même heure le lendemain, patiemment attend que la "chose se renouvelât", en dégustant une camomille: "Absurdement cette ligne lui paraissait devoir attirer maintenant le sort, ou le destin, ou la fatalité" (C. 41). Queneau attire l'attention sur le fait que même l'individu le plus civilisé retombe bien vite à son état animal. Les "philosophes" viennent au Palace de la Rigolade pour voir se soulever les jupes et les jupons des femmes placées sur des bouches d'air "ad hoc". Qu'un incident arrive et cette activité pacifique se mue en folie furieuse. Parallèlement il attribue aux animaux des caractéristiques humaines. Le meilleur exemple est sans doute le cas de Mésange et Pistolet qui accompagnent Pierrot dans la camionnette du cirque Mamar, sur la R. N. X bis. Pendant plusieurs pages, jusqu'à ce que la serveuse d'un restaurant hésite à les servir, le lecteur n'a absolument aucune idée de leur identité. Ils se comportent comme des êtres humains: "Mésange la regarda plein d'indifférence, de son oeil bistre et glauque tandis que Pistolet, que la conversation ennuyait, s'était endormi" (P. 140-143). Les compagnons de voyage de Pierrot étaient en fait un ours sauvage et un singe. Mais si l'homme ressemble parfois à un animal, il est doué de morale et d'intelligence et il a des aspirations et des idéaux, même s'ils n'apparaissent pas au grand jour. 
"C'est vrai, comment vivre sans idéal?... Sans idéal, on vit comme des animaux" (C. 282). Le colosse Gabriel se sort toujours des situations les plus scabreuses car il poursuit son idéal, se produire sur scène vêtu d'un tutu, aussi, la liberté, il en fait son affaire:

(il) assura son interlocuteur de l'étendue de la sienne, que de plus, il jugeait à sa convenance... finalement, s'étant adapté à la situation, il l'avait transformée à tel point que ses ravisseurs étaient devenus ses esclaves.... (Z. 118)

Prométhée enchaîné a des moyens de se libérer de ses chaînes et de répondre à l'absurdité de son monde environnant par des voies qui lui sont propres.

\section{SAGESSE POPULAIRE}

Le thêâtre de Gueneau c'est la ville, ses rues et ses bistrots, là où les hommes se rencontrent, assistent à des évènements surprenants, là où les "destins", les histoires se nouent et se dénouent, là où chacun se rassure au contact de son voisin, se laisse aller à des méditations intrigantes et intriguées, parfois inquiètes, sur la nature humaine. La ville, même si elle est décrite souvent dans ses aspects les plus sordides, Queneau la présente avec complaisance, sans agressivité. L'auteur a une représentation, pour le moins, ambivalente de la ville. Il fait dire à l'un de ses personnages que "l'homme ne s'accomplit que dans la ville". La nature et la campagne lui inspirent même de l'aversion:

Je déteste cette marge de verdure qui se répand autour de notre ville... C'est chez nous, derrière les pierres de nos constructions ou celles de nos rues, que l'on peut percevoir la vie; et c'est de là qu'elle rayonne vers l'obscurité de nos campagnes. (G.G. 127) 
Là où tout bouge, c'est bien évidemment la capitale: "Ah! Paris!... regarde-moi ça si c'est beau" s'écria Gabriel avec un enthousiasme gourmand ( $Z$. 14). Les beaux quartiers ne remuent guère avec leurs bonnes manières, et leurs masques figés, par contre la vraie vie se déroule dans les quartiers populaires, dans les petites rues, dans la banlieue et ses trains où la vie de chacun est réglée contre la montre et où tout incident est objet d'attention. Si la solitude est le refuge de certains héros de Queneau, c'est une solitude morale plus que physique. Tous mènent la vie sociale la plus courante: braves types, un peu naïfs ou râleurs, à la langue rapide et drue, ils travaillent, ils parlent sans arrêt, en un mot, ils font partie de la réalité de tous les jours. Tout cela ne fait appel qu'à leurs réflexes les plus mécaniques. Ils ont des collègues, des camarades de passage mais pas d'amis. Ils sont fondamentalement seuls pour résoudre leurs problèmes de tous les jours et pour se forger un monde à eux. Mais cette solitude, non seulement ils s'en accomodent, ils semblent même la rechercher et ne font aucun effort pour la rompre. Souvent même ils dissimulent des bâillements derrière un sourire contraint, et vont s'asseoir à l'écart pour reprendre leur monologue. En défendant leur position pour rester libre en leur for intérieur, ils s'assurent un îlot de sérénité autour d'une société tourmentée. Il arrive parfois cependant qu'ils éprouvent le besoin de se confier. Le premier venu devient un confident, silhouette imprécise qui disparait ensuite dans l'obscur. Cette absence de souffrance dans la solitude, sinon de contentement est bien un commencement de la sagesse. Autour d'eux, tout le monde leur prête des intentions; cependant, ils restent calmes et tranquilles: 
"Et puis j'ai une vie intéressante, mon histoire est instructive, exemplaire même" (C. 430). Même Pierrot, le moins "philosophe", n'est pas mécontent des plaisirs qu'il trouve au hasard de ses rencontres, des petits boulots qu'on lui propose et qui lui conviennent aussi courts soient-ils. Il sait jouir de son monde à lui, de celui qu'il se forge, il se plaît à penser tendrement à Yvonne;

... tout en en vidant sa bouteille de rouge, (il) sentait son crépuscule intérieur traversé de temps à autre par des fulgurations philosophiques, telles que: 'la vie vaut d'être vécue', ou bien: 'l'existence a du bon.' (P. 137)

Gabriel, dans Zazie, a trouvé son "truc" qui lui permet de répondre aux difficultés de la vie dont il a conscience; de tempéramment un peu vif, il a aussi ses élans de tendresse. Il accepte les autres tels qu'ils sont, masqués ou non, et il sait profiter des "petits bonheurs" de la vie "qui bercent et qui consolent" (Z. 174). Valentin du Dimanche de la vie, "inconscient" et "naïf" se contente d'être balayeur, hostile à toute agressivité à l'égard de ses collègues de caserne. Ceci entaîne le besoin d'être en retrait, de se dépersonnaliser et de devenir "transparent" pour ne pas faire souffrir les autres et ne leur causer aucune peine. Moins il attend de la vie et moins il exige de son cerveau, moins il sera alors frustré. La recherche du bonheur peut passer aussi par un usage raisonnable des plaisirs naturels. Le père Taupe est tenté par les cuisses d'Ernestine mais son bonheur fait de repos et de paix, de libération à l'égard des préjugés et des biens matériels aboutit à une austérité relative et à une autre forme de sagesse. Il refuse catégoriquement d'être compromis par l'argent. Son manque d'ambition et d'intérêt financier ne lui font 
pas redouter la ruine: "Parvenu au minimum de l'existence, il appréhendait de la dépasser... Il se croyait heureux, il se croyait sage" (C. 89). En réduisant ses attentes de la vie, il atteint la vraie satisfaction, inconnue de ceux qui l'entourent, et il en arrive à désigner son repaire désolé derrière la porte bleue comme "un petit coin de paradis au milieu de l'enfer de la banlieue parisienne" (C. 112). Mounnezergues, le gardien de la chapelle poldève, ne se laisse pas impressionner par les tractations financières que lui propose le propriétaire de Luni-Park, Pradonet, qui aime régner seul sur son domaine et voudrait agrandir ses biens. Pierrot refuse de se laisser abattre par la malchance, et en même temps n'aspire absolument pas à s'élever à un autre niveau. Ce qu'il a lui suffit et il en éprouve même une certaine satisfaction; il est indifférent aux jugements négatifs que son entourage ne cesse de lui répéter:

On ne lui avait jamais dit qu'il était intelligent. On lui avait plutôt répété qu'il se conduisait comme un manche ou qu'il avait des analogies avec la lune. En tout cas, ici, maintenant, il était heureux, et content, vaguement. (P.19)

La simplicité, le détachement des obsessions matérielles est ce qui caractérise bon nombre de personnages de Queneau; s'y ajoute aussi une perception particulière de ce qui les entoure. Valentin, naïf et innocent au début du Dimanche de la vie et qui ne remarque rien, a une vision des évènements et de la situation beaucoup plus claire à la fin; "impassible et immobile", observateur alerte et attentif, il surveille les folies de ses compagnons. La sagesse de Pierrot réside aussi dans sa faculté à prendre du recul par rapport aux valeurs qui compromettent la vision des autres. Lors de ses flâneries le long des 
rues de son quartier, il observe les vitrines des magasins qui exposent des vêlos et des timbres-poste et "les examinait avec la sévérité du connaisseur dégagé de tous les soucis de la possession, mais avec la satisfaction que donne ce désintéressement." (P. 175). Pierrot, homme sans histoire, en dehors des histoires, a néanmoins des qualités d'observation qui lui permettent de contempler des évidences, comme ce monument bizarre encastré dans l'Uni-Park, la chapelle poldève, là où gît le Prince Luigi, que d'autres personnages perdus dans le flux de la vie quotidienne, côtoient tous les jours sans l'avoir remarquée, ainsi l'aubergiste, qui, parlant de l'édifice en question répète à trois reprises: "Je ne vois pas" (P. 139-140). De même, il serait possible de rapprocher "la découverte" de Pierrot de l'êtonnement d'Etienne du Chiendent devant la baraque à frites ou devant les petits canards en caoutchouc qui flottent dans un chapeau rempli d'eau. C'est quand il perçoit lui-même les choses, qu'il acquiert un certain degré d'indépendance donc d'autonomie et de liberté. L"'illumination" d'Etienne correspond à l'accession d'une forme de sagesse qui est "La parfaite satisfaction accompagnée d'une plénitude de la conscience de soi" ( Kojève 389). Pradonet et la dame de l'auberge se vantent d'avoir "l'oeil américain" (P. 136) mais comme les voyantes du roman, ils ne voient rien venir (P. 9). Mme Cloche "renonça-z-à la vision", après avoir attendu en vain que "de nombreux écrasements" se produisent. Pierrot, lui, sait la différence entre voir et regarder, oeil nu ou vêtu de lentilles.

Le regard joue effectivement un grand rôle dans l'oeuvre de Queneau non seulement en tant que "vue" mais aussi en tant que 
"vision". Que ce soit au Palace de la Rigolade ou chez le fakir, on ne demande pas à Pierrot d'être clairvoyant, au contraire, on l'oblige à quitter ses lunettes. Il voit donc Crouïa-Bey s'enfoncer des dards d'acier dans les joues à travers le brouillard de sa myopie. Sans lunettes, il ne peut voir "le truc"; la réalité lui est masquée. Or Pierrot ne croit qu'en ce qu'il voit, et ce qu'il voit lui fait horreur: il s'évanouit. La sagesse de Pierrot est toute intérieure, aussi, sans lunettes, sans médiateur avec le monde extérieur. Petit-Pouce lui trouve une "tête à giffles" (P. 66), il l'agace car son bonheur discret est inaccessible aux autres. La quête et la sagesse de Pierrot se heurtent aux "tours" des fakirs et autres illusionnistes qui travestissent la vérité par intérêt. Le

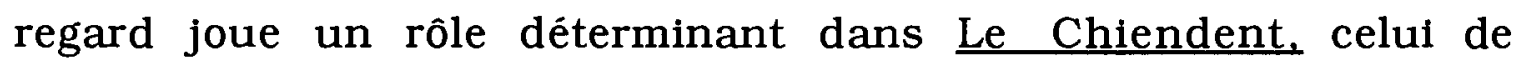
l'extérieur, c'est à dire celui de Pierre Le Grand qui permet à Etienne d'accéder à la conscience de soi. D'ailleurs, il dira de son observateur: "Lui il vit il a toujours existé il voit tout." En l'écoutant, il a cette réflexion: "En voilà un qui sait voir" (C. 82). C'est le regard du personnage qui détient la connaissance et donne naissance à l'autre. Dans l'intrigue, pour découvrir les intentions de l'autre, le regard est essentiel: "Le gênant, c'était les lunettes noires" (C. 343) du curé déguisé. La sagesse s'acquiert par un regard désintéressé: "Dès qu'on regarde les choses d'une façon désintéressée, tout change" dira Etienne (C. 183). Son coupe-oeufs-durs-en-tranches-minces qu'il avait rangé dans un tiroir, l'ayant acheté sans en connaître l'utilisation, "il le porta (plus tard) à la cuisine pour qu'on en fît usage" (C. 386). Valentin du Dimanche de la vie maittrise le temps des horloges selon "sa science" qu'il découvre progressivement au long du livre. De 
l'inconscience originelle, il est passé, comme Etienne Marcel, à la conscience de soi et au savoir. Au thème du regard s'ajoute aussi celui de la voyance qui va de pair avec la connaissance. Valentin Brû admire la vitrine de la mercerie tenue par sa future femme Julia;

... un foulard imprimé sur lequel on pouvait voir le Mont Saint-Michel. Pouvant le voir, Valentin le vit et il pensa que c'était un endroit à avoir vu. (D.V. 45)

La révélation des dons de voyance de Julia se réalise à partir d'un autre foulard imprimé;

Julia prit le foulard et elle vit alors une rue... Une dame marchait devant elle, sans aucun doute Madame Verterelle. Soudain, elle s'affaissait. Des gens accouraient. Et Julia sut qu'elle était morte. Julia vit... et Julia sut. (D.V. 124)

La connaissance est comparée à "une vue intérieure". Non seulement il faut savoir voir et regarder mais également se voir et se regarder. Queneau, en attachant de l'importance à la vue et au regard se réfère probablement aussi au complexe de Prométhée, symbole qu'utilisait Gaston Bachelard, regroupant sous ce terme toutes les tendances qui poussent " à savoir autant que nos pères, plus que nos pères, autant que nos maitres, plus que nos maitres" (Bachelard 30).

Dans d'autres romans, la poursuite de la connaissance et l'apprentissage sont un moyen de donner aux personnages un sens à leur vie, à condition que ce ne soit pas considéré comme une fin en soi (V.G. 99-103). Le thème est cependant effleuré dans Le Chiendent où M. Pic discute avec Thémistocle des applications de l'astronomie. Mounnezergues dans Pierrot est un autodidacte consciencieux qui veut connaître la dynastie poltève, et Valentin du Dimanche de la vie manifestant le désir de passer son baccalauréat, a déjà lu 
... de la première à la dernière page, les roses y compris, le petit dictionnaire Larousse français et encyclopédique, ce qui avait ouvert en lui les écluses du savoir,... mais il n'était pas sûr du sens du mot cénobite. (D.V. 64)

A travers ces personnages sympathiques, modestes, ces innocents "aux mains pleines", Queneau ne fait que mettre en évidence des manières différentes de se conduire dans la vie. La quête de la sagesse ne peut être qu'individuelle et c'est à chacun à la trouver en soi. Profiter des "petits bonheurs", c'est la réponse des personnages de Queneau à la fragilité de la vie et son absurdité tandis que la philosophie est à la recherche du Bonheur. Il n'y a pas de réponse universelle aux problèmes de l'univers. Queneau ne donne aucune réponse pas plus qu'il n'offre un modèle à suivre. Il faut savoir accepter la vie réelle avec toutes ses distorsions et ses aspects contradictoires en faisant preuve de tolérance:

Accepter la réalité, c'est l'accepter dans sa totalité, le plaisir comme la douleur, le bien comme le mal, le jour comme la nuit... Il faut accepter l'aspect négatif comme l'aspect positif des choses.... Il faut accepter l'anxiété non la fuir ou la déguiser; et l'on constatera alors que toute acceptation d'une perte devient alors un gain. (V.G. 172)

L'acceptation de la réalité, qui est une des caractéristiques de la sagesse, trouve souvent son expression à travers le rire qui est, somme toute, le moyen de "cultiver son jardin" (P. 57). 


\section{CHAPITRE V}

\section{AU-DELA DE L'HUMOUR}

Il y a un aspect jeu et distraction dans tout art.

- Raymond Queneau, Le Voyage en Grèce

Des personnages de Queneau répondent par le rire à leur situation désespérée. Pierrot assume sereinement son échec quand tout à la fin du roman, après un dernier regard sur les poubelles "il se mit à rire". "Julia s'étouffa de rire" à la fin également du Dimanche de la vie, rire dû au comique de la situation mais également moyen de s'en protéger. Tout au long de l'histoire, Julia a eu bien des difficultés à retenir son énigmatique Valentin, et au moment où elle pensait y être vraiment parvenue, elle aperçoit son mari, qui vient d'être démobilisé, manifestement très intéressé à aider quelques jeunes filles qui ne demandaient rien. Narcense a ri et a bien ri quand il s'est vu dans l'arbre avec le noeud coulant autour du cou; il fait part de ses impressions de pendu: "Le monde est passionnant, (dit-il), et la mort fait partie de ce monde" (C. 131). C'est à travers leurs éclats de rire que les personnages font face à leur malchance ou aux incidents malheureux. L'humour, dans ce cas, est basé sur la perception d'une disparité entre des aspirations présomptueuses et la réalité 
déprimante, et Queneau met constamment en valeur cette disparité de tous les aspects de la vie.

Pour Platon, le rire est essentiellement provoqué soit par la méchanceté soit par l'envie. Pour Aristote, il est dû à la vision d'une déformité morale ou physique. Ces deux théories recouvrent une forte dose d'agressivité. Or Queneau ne se moque ni ne méprise ses personnages, il ne porte aucun jugement sur eux. A l'un d'entre eux, Valentin Brû, dans Le Dimanche de la vie, il fait dire: "Au nom de quelle supériorité se permettrait-il de... se croire d'un degré au-dessus de ces paltoquets, de ces rombières et de ces morveux?" (D.V. 226). Molière, en simplifiant, caricaturant et exagérant, dévoile les vices, les travers et les ridicules des hommes. Ainsi le rire était un moyen sinon de les corriger au moins d'y réfléchir. Les lecteurs de Queneau, effectivement, rient de leurs propres défauts et de la façon dont ils parlent ou se conduisent. Selon Bergson, c'est la vision "du mécanique plaqué sur du vivant" qui provoque le rire (Bergson 29). L'exemple le plus net est sans doute le refrain du perroquet dans Zazie, qui gagne par contagion son propriétaire Turandot à la fin du roman ou les réflexions continuelles de Zazie; dans de tels cas, seul le son est pris en compte et non pas le sens des mots ou de la phrase. Lors du monologue de Gabriel au pied de la Tour Eiffel, l'humour vient, non pas d'une tension interne déplacée (au sens freudien du terme c'est à dire comme "moyen d'économie psychique"), mais dans le plaisir dû à une compression de l'énergie psychique:

Un forceps les amena, un corbillard les remporte et la tour se rouille et le Panthéon se fendille plus vite que les os des 
morts trop présents ne se dissolvent dans l'humus de la ville tout impregné de soucis. (Z. 91)

La présence exagérée du subjonctif et le discours déclamatoire sont en partis annulés par la banale expression "la tour se rouille."

L'humour implique le sérieux tout comme le comique cache le tragique. L'humour est intellectuel alors que le comique s'adresse aux sens. Chez Queneau il y a du comique, à la manière de Molière quí, en plus de la satire, jouait constamment à cache-cache avec la gravité ou l'amertume, mais l'ensemble de l'oeuvre de Queneau est essentiellement humoristique. L'humour, donc le rire qui en découle, vient des jeux de mots qui décrivent par exemple une situation, celle évoquēe à la première page des Fleurs bleues; mais il y a du sérieux dans ce plaisir ludique, c'est l'Histoire. La scène de l'enterrement de la grand-mère dans Le Chiendent est vue par le chien Jupiter qui pend, le lendemain, "au bout d'une corde à linge, entre un caleçon et une serviette, pour avoir attenté à la dignité des morts et des vivants" (C. 75). Ces deux derniers exemples provoquent l'éclat de rire: le tragique et le rire se superposent. Selon Queneau, "l'humour impose le sẻrieux par le comique" (V.G. 81). Humour et comique peuvent aussi être affaire de point de vue. C'est parce qu'il est nain que Bébé Toutout peut avouer: "Les girafes, je les trouve comiques; et les cochons d'Inde, émouvants" (C. 351). S'agit-il d'un problème d'éthique ou tout simplement de clairvoyance? C'est pour le moins, une façon élégante de lutter contre l'absurdité de la condition humaine. Le rire naît de notre connivence avec l'auteur qui traite de façon comique les questions fondamentales que chacun se pose. Comme Pierrot qui achève sa quête par un rire, Valentin qui 
déclenche le rire de sa femme ou Etienne qui rit de sa pendaison (ratée), chacun prend ses distances par rapport au monde dans lequel il vit; voilà une marque de compréhension et de sagesse.

Si "la connaissance" est utile, elle n'est qu'une partie de la réponse. Il faut arriver à une acceptation et une sagesse que chacun découvre et qui reste au niveau populaire. Ce populaire devient universel chez Queneau.

Comme l'oeuvre de Rabelais, celle de Queneau suscite mille interprétations, souvent difficiles à concilier. Elle n'est pas que divertissement et prétexte à rire, elle excite aussi la curiosité par son mélange de développements parfois obscurs et d'autres d'une telle simplicité que le sens réside au-delà des mots. A travers la désinvolture et l'invention verbale, Rabelais, d'une curiosité encyclopédique, a donné une leçon de l'humanisme du XVIe siècle, en mettant en évidence la participation libre et personnelle de l'individu dans le processus d'acquisition des connaissances, condition d'accès à la sagesse "philosophique". L'exergue du Dimanche de la vie. empruntée à $\mathrm{Hegel}^{1}$, reflète bien cet amour qu'a Queneau de l'humanité: "... des hommes doués d'une aussi bonne humeur ne peuvent être foncièrement mauvais ou vils." Les connaissances de l'auteur, tant scientifiques que littéraires, et son admiration pour les classiques et pour la Grèce, qui selon lui représente la "plénitude de l'être" (V.G. 58), sont autant de matériaux qu'il utilise parallèlement à

1 Par une interprettation assez lâche de humanior, le mot d'humanisme incomberait à Hegel qui pensait que dans les oeuvres de l'antiquité, l'honneur était fait à l'humain et au développement de l'humanitê. 
ses observations de la vie de tous les jours et des hommes qui l'entourent. Dans l'ensemble, le monde décrit par Queneau est simple et non-élitiste. L'auteur n'éprouve ni la pitié d'Honoré de Balzac, ni la fureur de Flaubert, ni la haine de Céline. Il ne méprise aucun individu, il les aime simplement sans chercher à les améliorer, il ne les juge pas, il ne juge personne. Il est curieux mais compréhensif. Il éprouve de l'estime pour certains, ceux qui "pensent" et qui représentent l'humanité consciente, et les autres plus vulnérables et un tantinet immatures, pas très intelligents, il faut le reconnaître, sont émouvants et attendrissants même si l'auteur s'en amuse de façon ambigüe. Reste une troisième catégorie, les "méchants", peu nombreux du reste, et auxquels Queneau ne prête qu'une attention désintéressée. De ses expériences personnelles qui constituent une autre forme de connaissance, il décrit, non pas la condition humaine mais la nature individuelle et humaine. Son humanisme ou plus exactement son sens de l'humanité, avec toutes ses contradictions et ses faiblesses, rappelle celui de Montaigne. Tout comme Montaigne, Queneau "pense que le savoir humain doit permettre à chacun de trouver un art de vivre raisonnablement, en attendant la mort."1 Et il le rejoint dans son amour de la franchise, de la civilitê, de l'équilibre de la conscience et dans sa haine du fanatisme et de la violence. Et au "Que sais-je?" de Montaigne, Queneau répond "Le peu que l'on peut apprendre... ce n'est en rêalitẻ qu'une ombre de savoir" (V.G. 99).

Mais moi je suis vivant et là s'arrête mon savoir Gabriel dans Zazle dans le métro

1 "Montaigne." Grand Larousse encyclopédique ıllustré. Tome 13 (1970) 
OUVRAGES CONSULTES

OEUVRES DE RAYMOND QUENEAU

Bâtons, chiffres et lettres. Paris: Gallimard, 1965. 2nd edit. Collection idées.

Cênt mille milliards de poèmes. Paris: Gallimard, 1961.

Exercices de style. Paris: Gallimard, 1947.

Le Chiendent. Paris: Gallimard, 1933. Collection folio.

Le Dimanche de la vie. Paris: Gallimard, 1952. Collection folio.

Le voyage en Grèce. Paris: Gallimard, 1973.

Les Fleurs bleues. Paris: Gallimard, 1965. Collection folio.

Pierrot mon ami. Paris: Gallimard, 1943. Collection Le livre de poche.

Saint- Glinglin précédé d'une nouvelle version de Gueule de Pierre et des Temps mêlés. Paris: Gallimard, 1948. Collection folio.

Zazie dans le mêtro. Paris: Gallimard, 1959. Collection folio.

\section{AUTRES OEUVRES}

Bachelard, Gaston. La psychanalyse du feu. Paris: Gallimard, 1949. Collection folio/essais.

Barthes, Roland. "Zazie et la littérature." Essais critiques. Paris: Seuil, 1964. 125-131.

Beaumarchais, J.P. de, et al. Dictionnaire des littératures de langue francaise. Vol 4. Paris: Bordas, 1987.

Bens, Jacques. Queneau. Paris: Gallimard, 962. Collection bibliothèque idéale. 
Benveniste, Emile. Problèmes de linguistique générale, 1. Paris: Gallimard, 1966. Collection TEL.

Bergson, Henri. Le Rire. Essai sur la signification du comique. Paris: Presses Universitaires de France, 1972. Collection bibliothèque de philosophie contemporaine.

Boyer, Régis. "Mots et jeux de mots chez Prévert, Queneau, Boris Vian, Ionesco: Essai d'étude méthodique." Studia Neophilologica, 40 (1968): 317-358.

Calame, Alain. "L'inversion géométrique." L'Herne, 29 (1975): 263271.

Calame, Alain. "Les Fleurs bleues: rime et concordance." Temps mêlës, 150 (1983): 17-19.

Charbonnier, Georges. Entretiens avec Raymond Queneau. Paris: Gallimard, 1962.

Chevalier, Jean et Alain Gheerbrant. Dictionnaire des symboles. Ed. revue et corrigée. Paris: Robert Laffont, 1982.

Doppagne, Albert. "Le Néologisme chez Raymond Queneau." Cahiers de l'Association Internationale des Etudes Francalses, 25 (1973): 91-107.

Gayot, Paul. Raymond Queneau. Paris: Editions Universitaires, 1967.

Gobert, L. David. "The Essential Character In Queneau's 'Zazie dans le métro'." Symposium, vol 40 (1986): 91-105.

Greimas, A. J. Sémantique structurale. Paris: Larousse, 1966.

Guicharnaud, Jacques. Raymond Queneau. Ed. William York Tindall. New York \& London: Columbia University Press, 1965.

Hale, Jane Alison. The Lyric Encyclopedia of Raymond Queneau. Ann Arbor: The University of Michigan Press, 1989.

Hedges, Inez. "Form and Meaning in the French Film, IV: Language." The French Review, 58 (1984): 223-235.

Kojève, Alexandre. "Les romans de la sagesse." Critique, 60 (1952): 387-397.

Lavine, T.Z. From Socrates to Sartre: The Philosophic Quest. New York: Bantam Books, 1984. 
Mercier, Vivian. "Raymond Queneau: The creator as Destroyer." The New Novel From Queneau To Pinget. New York: Farrar, Straus, and Giroux, 1971. 43-103.

Pouilloux, Jean-Yves. Les Fleurs bleues de Raymond Queneau. Paris: Gallimard, 1991. Collection Foliothèque.

Prince, Gerald. "Queneau et l'anti-roman." Neophilologus, 55 (1971): 33-40.

Queval, Jean. Essai sur Raymond Queneau. Paris: P. Seghers, 1960. Collection Poètes d'aujourd'hui.

Rędfern, W.D. Queneau, Zazie dans le Métro. Ed. Roger Little, Wolfgang Van Emden, and David Williams. London: Grant \& Cutler, 1980.

Robbe-Grillet, Alain. Pour un nouveau roman. Paris: Gallimard, 1963. Collection idées.

Saussure, Ferdinand de. Cours de linguistique générale. Publié par C. Bally et A. Sechehaye. Paris: Payot, 1978. Collection Payothèque.

Shorley, Christopher. Queneau's fiction: An Introduction Study. Cambridge: Cambridge University Press, 1985.

Simonnet, Claude. Queneau déchiffré (Notes sur 'Le Chiendent'). 2nd edit. Genève: Slatkine, 1981.

Souchier, Emmanuël. Raymond Queneau. Paris: Les ContemporainsSeuil, 1991.

Targe, André. "Un métro nommé Bonheur." Poétique, 29 (1977): 6176.

Thiher, Allen. Raymond Queneau. Ed. David O'Connell. Boston: Twayne, 1985.

Von Wartburg, Walter. Evolution et structure de la langue francaise. 10th edit. Berne: Francke, 1971. Collection bibliotheca romanica.

Von Wartburg, W. et Stephen Ullmann. Problèmes et méthodes de la linguistique. Paris: Presses Universitaires de France, 1969. Collection SUP. 
APPENDICE A

\section{BIOGRAPHIE DE RAYMOND QUENEAU}

(d'après le Dictionnaire des littératures de langue francaise et Raymond Queneau d'Emmanuël Souchier)

Le rapport de l'homme à l'oeuvre, quolqu'on en pense dans un esprit classique, ce n'est pas une recherche méprisable.

- Raymond Queneau, Bâtons, chiffres et lettres 


\begin{tabular}{|c|c|c|c|c|}
\hline \multicolumn{2}{|c|}{ VIE ET EVENEMENTS NOTABLES } & \multicolumn{3}{|c|}{ OEUVRES } \\
\hline 1903 & $\begin{array}{l}\text { Naissance, au Havre, le } 21 \\
\text { février, de Raymond Gueneau, } \\
\text { flls de commerçants } \\
\text { (mercerie). }\end{array}$ & & & \\
\hline $\begin{array}{l}1908- \\
1920\end{array}$ & $\begin{array}{l}\text { Etudes au lycée du Havre et } \\
\text { baccalauréat. Comence à } \\
\text { ëcrire, lit assidument Les Pieds } \\
\text { Nickelés et va régulièrement } \\
\text { au cinéma. }\end{array}$ & & & \\
\hline $\begin{array}{l}1920- \\
1925\end{array}$ & $\begin{array}{l}\text { Licence de philosophie en } \\
\text { Sorbonne. }\end{array}$ & & & \\
\hline & Habite Epinay-sur-Orge. & & & \\
\hline 1922 & Séjour en Angleterre. & & & \\
\hline 1924 & $\begin{array}{l}\text { Rencontre avec André Breton } \\
\text { en hiver, participe aux } \\
\text { acttutés du groupe surrealiste. }\end{array}$ & 1924 & $\begin{array}{l}\text { Publications dans } L a \\
\text { révolution surréaliste. }\end{array}$ & Essais \\
\hline $\begin{array}{l}1925- \\
1927\end{array}$ & $\begin{array}{l}\text { Service militaire en } \\
\text { Allemagne et au Maroc. } \\
\text { Zouave de 2e classe. Sult des } \\
\text { cours d'anglais commercial et } \\
\text { de techniques de vente par } \\
\text { correspondance. }\end{array}$ & & & \\
\hline & $\begin{array}{l}\text { Amitiés avec Tanguy, Prévert } \\
\text { et Duhamel. }\end{array}$ & & & \\
\hline 1928 & $\begin{array}{l}\text { Epouse Janine Kahn, belle- } \\
\text { soeur de Breton. }\end{array}$ & & & \\
\hline $\begin{array}{l}1928- \\
1930\end{array}$ & $\begin{array}{l}\text { Première période picturale } \\
\text { (aquarelles). }\end{array}$ & 1928 & Pictogrammes & Essais \\
\hline 1929 & Rupture avec André Breton. & & & \\
\hline & Lit l'Ulysse de James Joyce. & & & \\
\hline
\end{tabular}




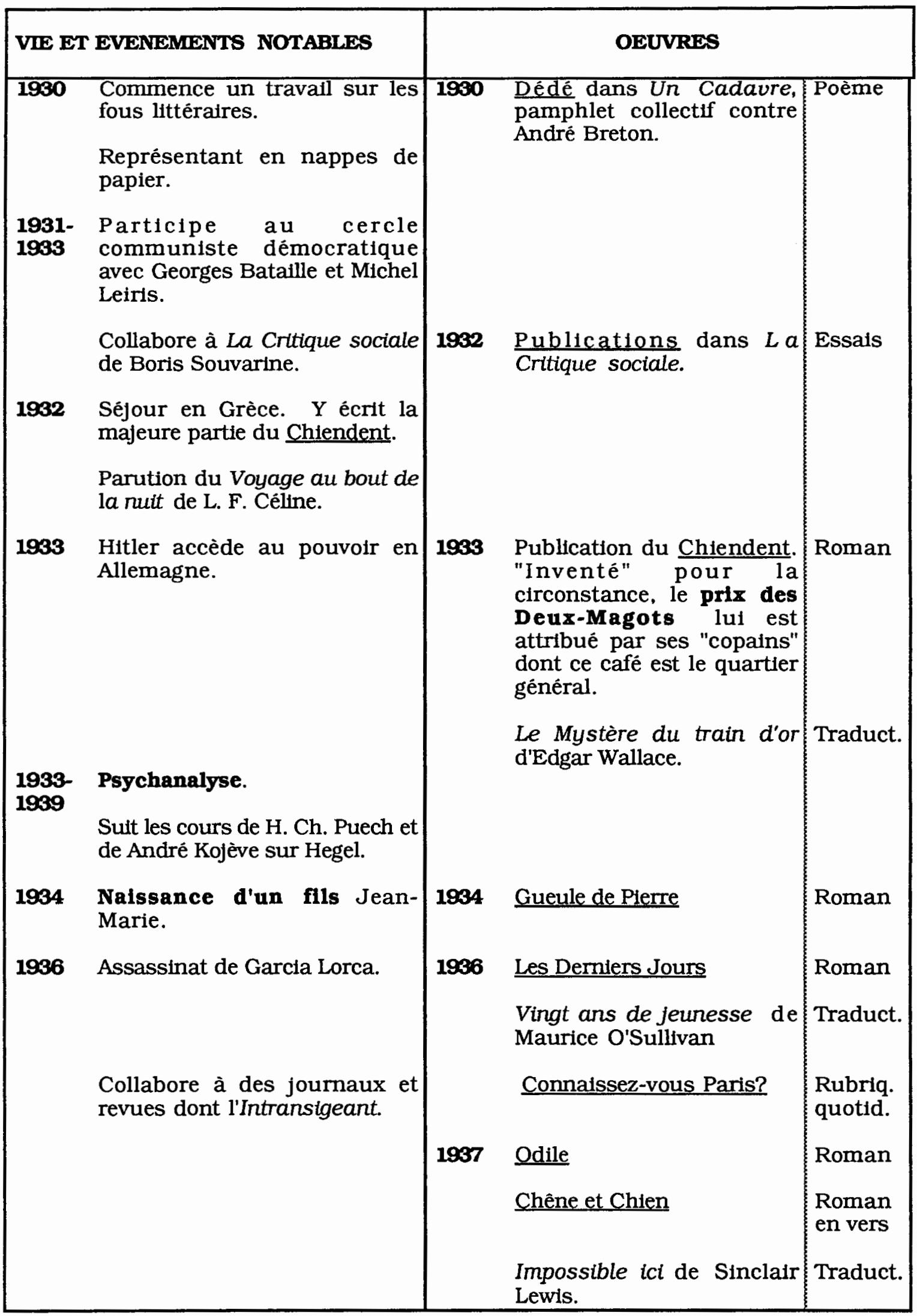




\begin{tabular}{|c|c|c|c|c|}
\hline VIE E & S NOTABLES & \multicolumn{3}{|c|}{ OEUVRES } \\
\hline 1938 & $\begin{array}{l}\text { Accords de Munich. } \\
\text { Entre au comité de lecture des } \\
\text { Editions Gallimard (anglais). } \\
\text { Fonde Volontés avec Henri } \\
\text { Miller. } \\
\text { J.P. Sartre publie La Nausée. }\end{array}$ & 1938 & $\begin{array}{l}\text { Les Enfants du limon (une } \\
\text { voix au Goncourt) } \\
\text { L'homme de William } \\
\text { Saroyan. }\end{array}$ & $\begin{array}{l}\text { Roman } \\
\text { Traduct. }\end{array}$ \\
\hline 1939 & $\begin{array}{l}\text { Déclaration de guerre. } \\
\text { Mobilisé. }\end{array}$ & 1999 & $\begin{array}{l}\text { Un rude hiver } \\
\text { Panique }\end{array}$ & $\begin{array}{l}\text { Roman } \\
\text { Nouv. }\end{array}$ \\
\hline 1940 & Démobilisé. & & $\begin{array}{l}\text { Le Zeppelin de William } \\
\text { Saroyan. }\end{array}$ & Traduct. \\
\hline 1941 & $\begin{array}{l}\text { Secrétaire général des Editions } \\
\text { Gallimard. }\end{array}$ & $\begin{array}{l}1941 \\
1942\end{array}$ & $\begin{array}{l}\text { Les Temps mêlés } \\
\text { Pterrot mon ami } \\
\text { Dino } \\
\text { Les Ziaux. } \\
\text { Introduction à Bouvard et } \\
\text { Pecuchet. }\end{array}$ & $\begin{array}{l}\text { Roman } \\
\text { Roman } \\
\text { Nouv. } \\
\text { Poèmes } \\
\text { Essais }\end{array}$ \\
\hline $\begin{array}{l}1944- \\
1945\end{array}$ & $\begin{array}{l}\text { Organisateur des Matinées } \\
\text { poétiques de la Comédie- } \\
\text { Française avec J. L. Barrault. } \\
\text { Parution de Paroles de Jacques } \\
\text { Prévert. } \\
\text { Capitulation allemande. } \\
\text { Bombe atomique sur } \\
\text { Hiroshima. }\end{array}$ & $\begin{array}{l}1944 \\
1945\end{array}$ & $\begin{array}{l}\text { En passant } \\
\text { Front national } \\
\text { Loin de Rueil } \\
\text { Foutalses }\end{array}$ & $\begin{array}{l}\text { Théâtre } \\
\text { Chront- } \\
\text { que } \\
\text { Roman } \\
\text { Roman }\end{array}$ \\
\hline 1946 & $\begin{array}{l}\text { Seconde période picturale } \\
\text { (gouaches). }\end{array}$ & 1946 & $\begin{array}{l}\text { Peter Ibbetson de George du } \\
\text { Maurier. }\end{array}$ & Traduct. \\
\hline
\end{tabular}




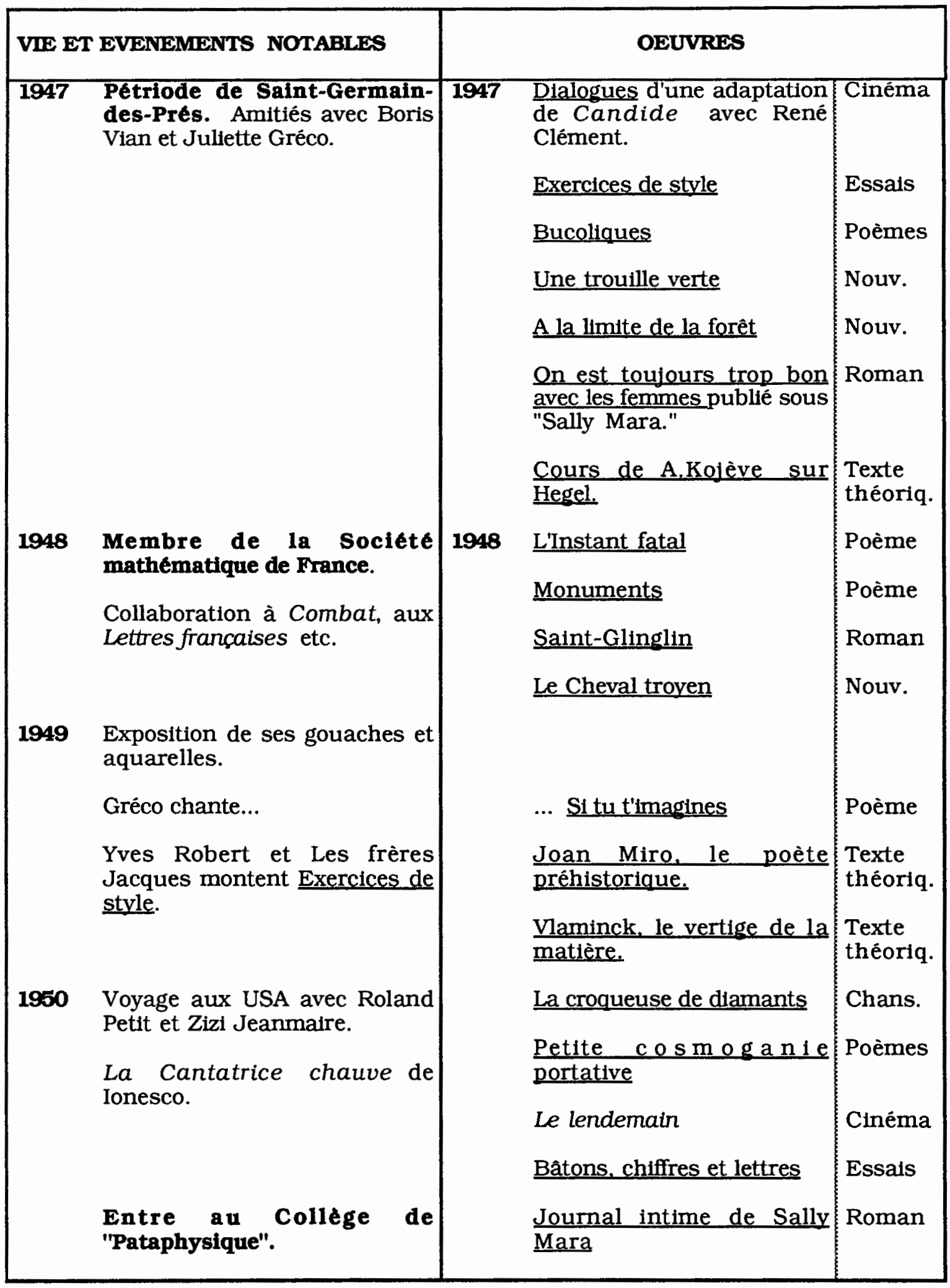




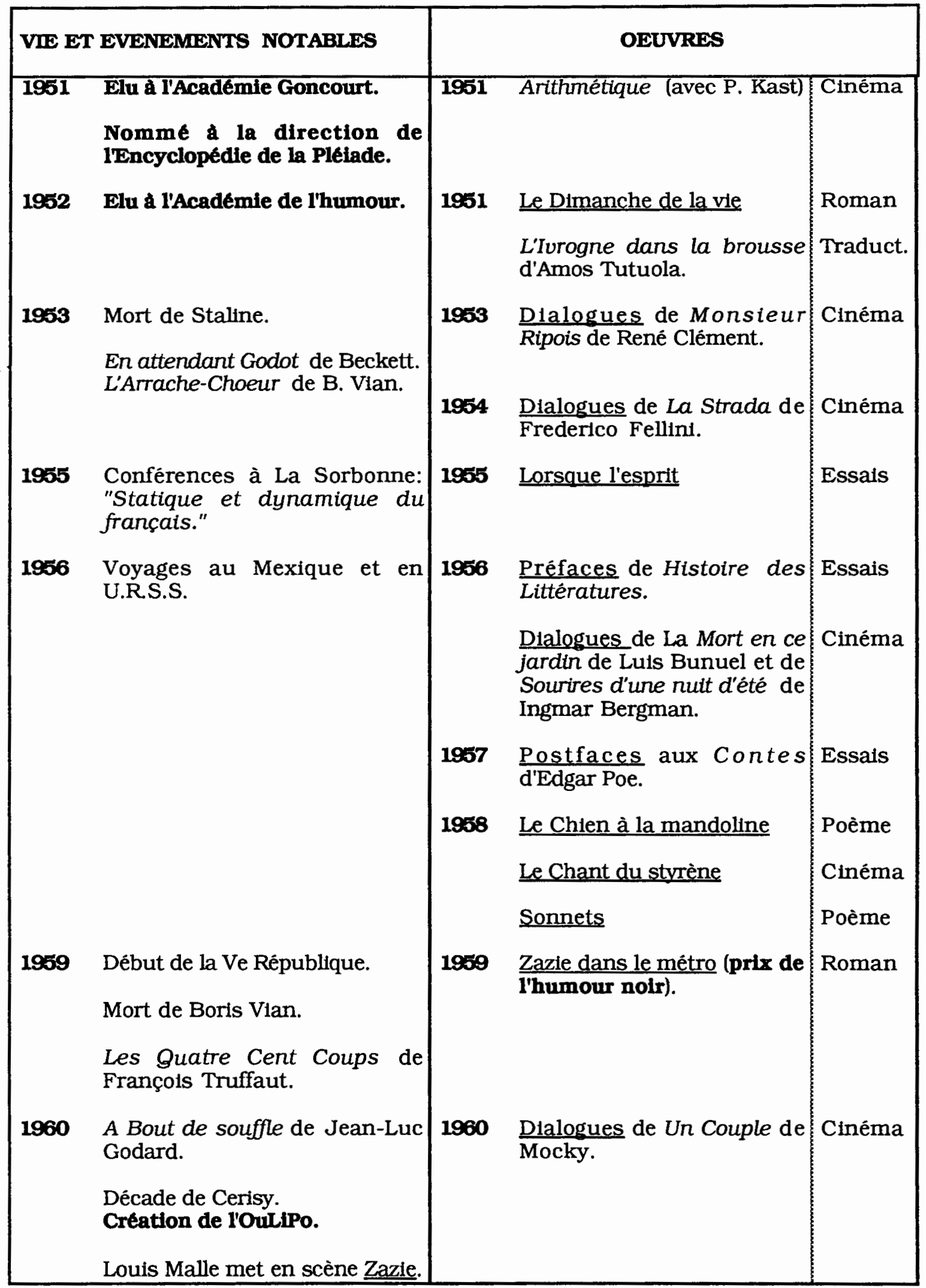




\begin{tabular}{|c|c|c|c|c|}
\hline \multicolumn{2}{|c|}{ VIE ET EVENEMENTS NOTABLES } & \multicolumn{3}{|c|}{ OEUVRES } \\
\hline 1961 & $\begin{array}{l}\text { Loin de Rueil au TNP par Jean } \\
\text { Vilar. }\end{array}$ & 1961 & $\begin{array}{l}\text { Cent Mille Milliards de } \\
\text { poèmes } \\
\text { Texticules }\end{array}$ & $\begin{array}{l}\text { Poèmes } \\
\text { Roman }\end{array}$ \\
\hline \multirow[t]{14}{*}{1962} & $\begin{array}{l}\text { Entretiens radiodiffusés avec } \\
\text { Georges Charbonnier. } \\
\text { Joue Clémenceau dans Landru } \\
\text { de Chabrol. }\end{array}$ & 1962 & $\begin{array}{l}\text { Oeuvres complètes de Sally } \\
\underline{\text { Mara. }}\end{array}$ & \\
\hline & & 1963 & Bords & Essais \\
\hline & & 1964 & $\begin{array}{l}\text { L'Analyse matricielle } \mathrm{d} u \\
\text { langage }\end{array}$ & $\begin{array}{l}\text { Texte } \\
\text { théoriq. }\end{array}$ \\
\hline & & 1965 & Les Fleurs bleues & Roman \\
\hline & & 1966 & Une histoire modèle & Essals \\
\hline & & 1967 & $\underline{\text { L'Emploi du temps }}$ & Cinéma \\
\hline & & & Courtr les rues & Poème \\
\hline & & & Un conte à votre facon & Roman \\
\hline & & 1968 & Battre la campagne & Poème \\
\hline & & & Regards sur Paris & Essals \\
\hline & & & $\underline{\text { Le Vol d'Icare }}$ & Roman \\
\hline & & 1969 & Fendre les flots & Poème \\
\hline & & 1971 & $\begin{array}{l}\text { De quelques langages } \\
\text { animaux... }\end{array}$ & Essals \\
\hline & & & $\begin{array}{l}\text { Les fondements de la } \\
\text { littérature }\end{array}$ & $\begin{array}{l}\text { Texte } \\
\text { théoriq. }\end{array}$ \\
\hline \multirow[t]{4}{*}{1972} & $\begin{array}{l}\text { Mort de sa femme Janine. Très } \\
\text { affecté par ce deuil. }\end{array}$ & & & \\
\hline & & 1973 & Le voyage en Grèce & Essals \\
\hline & & & Récit de rêves à foison & Roman \\
\hline & & 1975 & Morale élémentaire & Poèmes \\
\hline 1976 & $\begin{array}{l}\text { Mort de Raymond Gueneau le } \\
25 \text { octobre. }\end{array}$ & & & \\
\hline
\end{tabular}




\begin{tabular}{|c|c|c|c|}
\hline & \multicolumn{3}{|c|}{ OEUVRES ET EDITIONS POSTHUMES } \\
\hline & $\begin{array}{l}1981 \\
1986 \\
1989 \\
1990\end{array}$ & $\begin{array}{l}\text { Publication de Contes et } \\
\text { Propos. } \\
\text { Publication de Journal } \\
\text { 1939-1940. } \\
\text { Comprendre la folie } \\
\text { Oeuvres complètes, vol. I, } \\
\text { Pléiade. } \\
\text { Gustave Le Bon } \\
\text { Les vertus démocratiques } \\
\text { Oeuvres complètes, vol. II et } \\
\text { III, Pléiade. }\end{array}$ & $\begin{array}{l}\text { Roman } \\
\text { Essais } \\
\text { Essais } \\
\text { Essais } \\
\text { Inédit } \\
\text { A } \\
\text { paraître }\end{array}$ \\
\hline
\end{tabular}


APPENDICE B

ABRÉVIATIONS UTILISÉES

POUR LES OEUVRES DE QUENEAU

CITÉES EN RÉFÉRENCES 
B.c.l. Bâtons, chiffres et lettres

C. Le Chiendent

D.V. Le Dimanche de la vie

FB. Les Fleurs bleues

P.c.p. Petite cosmogonie portative

P. Pierrot mon ami

G.G. Saint-Glinglin

V.G. Le voyage en Grèce

Z. Zazie dans le métro 